\title{
Ácaros Associados à Jatropha spp. (Euphorbiaceae) no Brasil.
}

\author{
Rodrigo Luiz Costa Verona
}




\section{Universidade Estadual Paulista Instituto de Biociências, Letras e Ciências Exatas São José do Rio Preto, SP.}

Programa de Pós-graduação em Biologia Animal

Rodrigo Luiz Costa Verona

Ácaros associados à Jatropha spp. (Euphorbiaceae) no Brasil.

Orientador: Prof. Dr. Antonio Carlos Lofego 


\section{Rodrigo Luiz Costa Verona}

Ácaros associados à Jatropha spp. (Euphorbiaceae) no Brasil.

Data da defesa: 26/03/2010

Dissertação apresentada para obtenção do título de Mestre em Biologia Animal, Depto. de Zoologia e Botânica, programa de pós-graduação em Biologia Animal - Instituto de Biociências, Letras e Ciências Exatas, Universidade Estadual Paulista UNESP “Júlio de Mesquita Filho".

Banca Examinadora:

Prof. Dr. Antonio Carlos Lofego

Unesp - S. J. Rio Preto-SP

Orientador

Prof. Dr. Reinaldo J. F. Feres

Unesp - S. J. Rio Preto-SP

Prof. Dr. Gilberto José de Moraes

Usp - Piracicaba-SP

S. J. Rio Preto, 26/03/2010 


\section{Agradecimentos}

- Ao Prof. Antonio Carlos Lofego - Unesp, S. J. Rio Preto, pela orientação durante $o$ mestrado e pela colaboração em minha formação pessoal e profissional;

- Ao Prof. Dr. Reinaldo J. F. Feres - Unesp, S. J. Rio Preto, pelas sugestões durante a elaboração desse trabalho e pela identificação dos ácaros da família Tetranychidae.

- A minha esposa Fernanda Verona pela companhia e incentivo durante o curso de mestrado.

- Aos amigos do Laboratório de Acarologia - Unesp, S. J. Rio Preto - SP: Raquel, Peterson, Barbara, Eliseu, Rodrigo (Yoda), Fábio, Eduardo, Pérola, Fernanda, Fernanda Verona, Felipe, José Cesar, José Marcos, Adriano e Tarcisio.

- José César de Souza pelo companheirismo e ajuda nas coletas do nordeste;

- Peterson Rodrigo Demite pela leitura crítica do capítulo I;

- Casa da Agricultura de Jales-SP pela cooperação nas coletas em campo e informação dos dados climáticos;

- Aos produtores Carlos Alberto Bertolino e Valtrudes Sírio "Didi" de ItapagipeMG e Marcus Merotti e Shoiti Kamimura de Jales-SP pela concessão de suas lavouras para a realização desse estudo.

- Jerônimo Donizete da Silva pela colaboração na escolha das áreas em Itapagipe-MG.

- José Marcos Rezende pelo companheirismo e ajuda na seleção de lavouras, manutenção da lavoura experimental e obtenção dos dados climáticos em Itapagipe - MG;

- Felipe Nuvoloni e Tiago Gonçalves-Souza pela colaboração nas análises estatísticas.

- Aos agrônomos Danielle de Lourdes Batista Moraes e Jorge Kakida (Biojam, Janaúba, MG) pelo auxílio nas coletas no norte de Minas Gerais. 
Dedicatória

Aos acarólogos. 
"Com a mesma inevitabilidade pela qual uma pedra cai ao chão, o lobo faminto enterra as presas na carne de sua vítima, sem a consequência de representar ao mesmo tempo, o destruído e o destruidor".

Arthur Schopenhauer 


\section{SUMÁRIO}

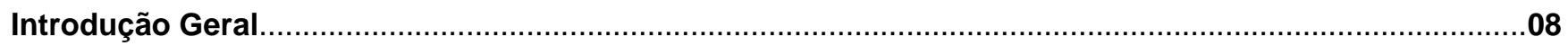

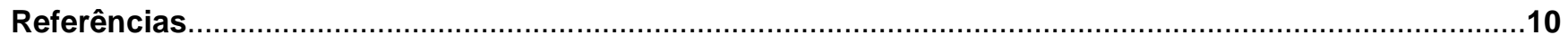

\section{CAPÍTULO I}

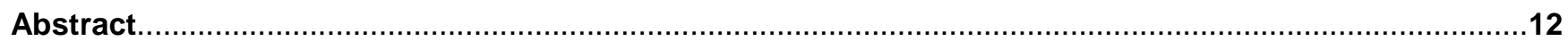

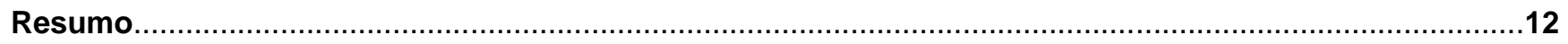

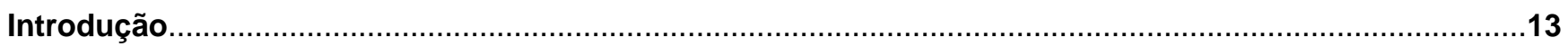

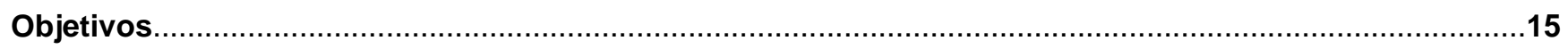

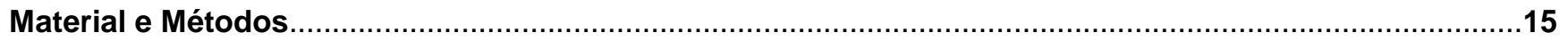

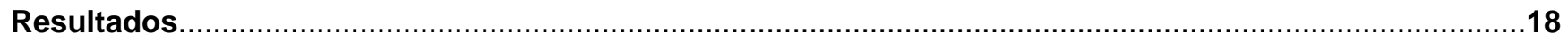

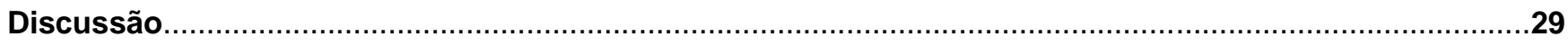

Referências.

\section{CAPÍTULO II}

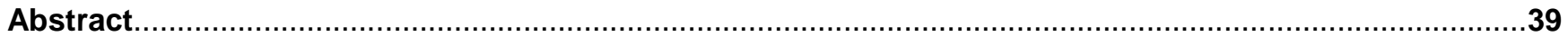

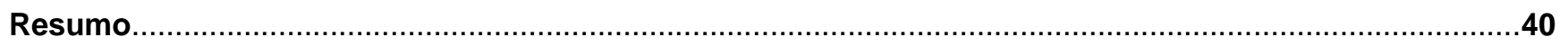

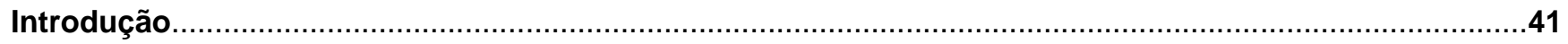

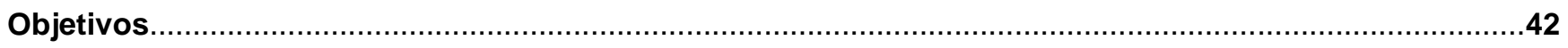

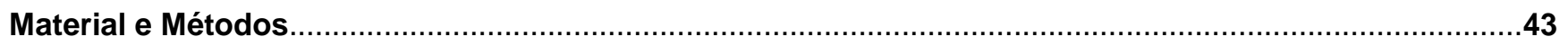

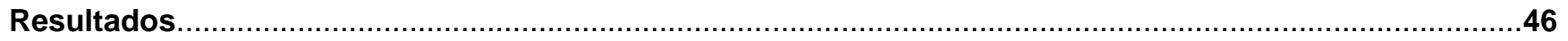

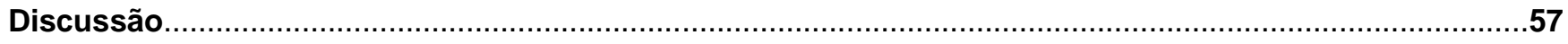

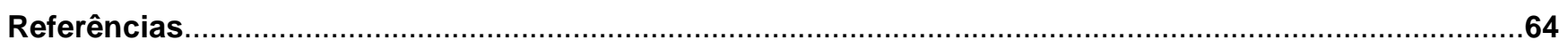

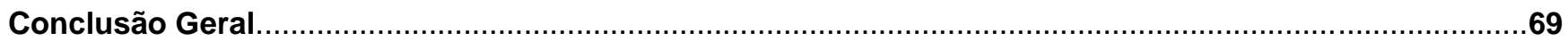


ÍNDICE DE FIGURAS E TABELAS

CAPÍTULO I

Figura 1. Pontos de coleta em exemplares de J. curcas nos municípios de Jales (SP) e Itapagipe (MG)

Figura 2. Pontos de coleta em exemplares de J. curcas em vários municípios do norte de Minas Gerais e nordeste brasileiro

Tabela 1. Pontos de coleta em J. curcas, J. gossypiifolia e J. mollissima no Brasil

\section{CAPÍTULO II}

Figura 01. Ocorrência sazonal das espécies de ácaros mais abundantes em Jatropha curcas L. (Euphorbiaceae) na lavoura A, Jales - SP.

Figura 02. Ocorrência sazonal das espécies mais abundantes de fitoseídeos em J. curcas L. (Euphorbiaceae) na lavoura B, Jales $-\mathrm{SP}$......

Figura 03. Ocorrência sazonal das espécies mais abundantes de ácaros fitófagos em J. curcas L. (Euphorbiaceae) na lavoura B, Jales - SP.

Figura 04. Ocorrência sazonal das espécies de ácaros mais abundantes em Jatropha curcas L. (Euphorbiaceae) na lavoura $C$, Itapagipe - MG......

Figura 5. Ocorrência sazonal das espécies de ácaros em Jatropha curcas L. (Euphorbiaceae) na lavoura D, Itapagipe - MG.....

Figura 6. Ocorrência sazonal da espécie de ácaro mais abundante em Jatropha curcas L. Euphorbiaceae) na lavoura D, Itapagipe - MG.

Figura 7. Correlação entre a população de $P$. latus e o índice pluviométrico na lavoura $D$, Itapagipe-MG, 2008/09

Figura 8. Curva de componente de dominância das espécies de ácaros encontradas em lavouras de J. curcas em Jales-SP e Itapagipe-MG......

Figura 9. Médias e desvios das diferenças entre as comunidades de ácaros encontradas nos diferentes modelos de manejo em lavoura experimental de J. curcas em Itapagipe-MG. Predadores compreendem as famílias Phytoseiidae e Iolinidae e fitófagos as famílias Tarsonemidae e Tenuipalpidae. a e b indicam diferença significativa $(p=0.02)$.

Tabela 1. Lista de espécies de ácaros coletadas em Itapagipe - MG e Jales SP, maio de 2008 à abril de 2009.

Tabela 2. Índices de diversidade, diversidade máxima teórica e homogeneidade das lavouras estudadas em Jales SP e Itapagipe - MG, maio de 2008 a abril de 2009.

Tabela 03. Espécies de ácaros registradas em lavoura experimental em Itapagipe - MG. Número de indivíduos encontrados por área e índices de diversidade correspondentes a cada uma das áreas estudadas..... 


\section{Introdução geral}

O pinhão manso (Jatropha curcas L.) é uma espécie vegetal arbustiva da família das Euforbiáceas, nativa da América tropical. Também conhecido como pinhão-bravo, pinhão-de-purga, purgante-de-cavalo, pião, pinhão-de-cerca, figo-do-inferno, mandabiguaçú (OLIVEIRA \& AKISUE, 2008), J. curcas é um arbusto perene, atingindo cerca de três metros de altura e caule bojudo na base. Suas folhas são amareloesverdeadas, alternas, pecioladas, providas de contorno orbicular, palmatilobadas com cinco lobos. As flores são pequenas, agrupadas e de sexos separados. Possui um fruto capsular ovóide, trilocular, com uma semente em cada cavidade (BRASIL, 1985). Segundo Silveira (1934) apud Arruda et al. (2004) e Braga (1976), cada semente de pinhão manso pode conter de 25 a 40\% de óleo inodoro de fácil extração.

A distribuição geográfica do pinhão manso é bastante vasta devido à sua rusticidade, resistência a longas estiagens, bem como a pragas e doenças, sendo adaptável a condições edafo-climáticas muito variáveis. Desenvolve-se bem tanto em regiões tropicais secas como nas zonas equatoriais úmidas, assim como em terrenos áridos e pedregosos podendo suportar longos períodos de seca (ARRUDA et al., 2004). De acordo com Saturnino et al. (2005), pode-se encontrar pinhão manso em todas regiões tropicais e até mesmo em algumas áreas temperadas.

Atualmente esse vegetal tem despertado a atenção de produtores devido ao seu potencial como matéria prima para produção de biodiesel. No entanto, muito pouco é conhecido desta planta, em relação à sua fisiologia, bioquímica e até mesmo aspectos agronômicos. Somente nos últimos 30 anos, é que estudos agronômicos foram 
iniciados, já que se trata de uma planta ainda não domesticada (SATURNINO et al., 2005).

Com relação à acarofauna associada a essa planta, são poucas as informações disponíveis na literatura. No entanto, alguns ácaros fitófagos já têm sido citados como potenciais pragas para essa espécie vegetal, como Polyphagotarsonemus latus BANKS (Heterostigmata: Tarsonemidae) e Tetranychus bastosi Tuttle, Baker \& Sales (Prostigmata: Tetranychidae) (ALBUQUERQUE et al., 2006; SANTOS et al., 2006).

Um dos principais fatores na queda de produtividade em qualquer cultivo é o aparecimento de pragas. São notáveis os problemas de importância econômica ocasionados por ácaros em plantas cultivadas (JEPPSON et al., 1975), no entanto, o cultivo do pinhão manso ainda é muito recente e pouco estudado e, a fauna associada a esse vegetal é muito pouco conhecida tanto no Brasil como no mundo.

O conhecimento da comunidade acarina pode colaborar para o estudo de possíveis pragas assim como na detecção de predadores naturais (BARBOSA et al., 2003). 


\section{Referências}

ARRUdA, F.P. de; BELTRÃO, N.E. de M.; ANDRADE, A. P. de; PEREIRA, W.E.; SEVERINO, L.S. 2004. Cultivo de Pinhão manso (Jatropha Curcas L.) como alternativa para o semi-árido Nordestino. Revista Brasileira de Oleaginosas e Fibrosas, Campina Grande. v.8, p. 789-799.

BARBOSA, J. C. D.; NIED, A. H.; VENDRUSCOLO, M. C.;SANTOS, R. P.;GERALDI, L. 2003. Produtividade do pinhão manso (Jatrophas curcas L.) em diferentes densidades e épocas no primeiro ano em Tangará da Serra-MT. Revista Brasileira de Oleaginosas e Fibrosas, Campina Grande.

BRAGA, R. 1976. Plantas do Nordeste, especialmente do Ceará. 3 ed. In: congresso brasileiro de florestas tropicais. Escola Superior de Agricultura de Mossoró. p.412413.

BRASIL, Ministério da indústria e do comércio. Secretária de tecnologia industrial. 1985. "Produção de combustíveis líquidos a partir de óleos vegetais". Ministério da indústria e do comércio, Brasília.

JEPPSON, L.R.; KEIFER H.H.; BAKER E.W. Mites injurious to economic plants. Berkeley, University of California Press, 1975. 614p.

OLIVEIRA, F.; AKISUE, G. 2008. Fundamentos de Farmacobotânica e de Morfologia Vegetal. Atheneu. 228p.

SANTOS, H. S; CARVALHO, S. V. A; BOARI, A. J; RIBEIRO, G. T; NAVIA, D. 2006. O ácaro Tetranychus bastosi TUTTLE, BAKER \& SALES (Prostigmata: Tetranychidae) infestando germoplasma nativo de Jatropha sp. no Estado do Sergipe, Brasil. $2^{\circ}$ Congresso Brasileiro de Mamona, Sergipe. 2ํㅡㄹ Congresso Brasileiro de Mamona Cenário atual e perspectivas.

SATURNINO, H. M.; PACHECO, D. D.; KAKIDA, J.; TOMINAGA, N.; GONÇALVES, N.P. 2005. Cultura do pinhão-manso (Jatropha curcas L.). Informe Agropecuário, v. 26, p.44-78. 
Capítulo I. Levantamento da acarofauna em Jatropha spp. (Euphorbiaceae) no Noroeste do Estado de São Paulo, Triângulo Mineiro e Nordeste do Brasil.

Rodrigo Luiz Costa Verona 
Abstract: Jatropha curcas $L$. is a plant species that has a high oil content that can be used as a substitute for diesel engine oil. This way, there is a great interest on the part of producers for the deployment of this culture. However, the mite fauna associated with this plant is not yet known. For the purpose to known the mite fauna associated with $J$. curcas were done surveys in crops in Jales, State of São Paulo and Itapagipe, State of Minas Gerais, plus samplings carried out at various points by Northeast Brazil, including sampling of two other species: J. mollissima and J. gossypiifolia. Twenty-five species of mites were found associated with $J$. curcas, belonging to the families: Phytoseiidae, Tetranychidae, Tarsonemidae, Tenuipalpidae, Winterschmidtiidae, Iolinidae, Cryptognathidae, Cunaxidae and Ascidae. Two of them have the potential to become pests: Polyphagotarsonemus latus (Heterostigmata: Tarsonemidae) and Tetranychus bastosi (Prostigmata: Tetranychidae).

Key words: Jatropha spp. Faunistic survey. Plant's mites.

Resumo: Jatropha curcas L. é uma espécie vegetal que possui um alto teor de óleo que pode ser usado como um substituto para o diesel em motores a óleo. Dessa maneira, existe um grande interesse por parte dos produtores para a implantação dessa cultura. No entanto, a acarofauna associada a esse vegetal ainda não é conhecida. Com o propósito de levantar as espécies de ácaros associados à J. curcas, foram realizadas coletas em culturas em Jales, estado de São Paulo e Itapagipe, estado de Minas Gerais, além de amostragens realizadas em vários pontos pelo nordeste brasileiro, inclusive com amostragem de outras duas espécies: J. mollissima e J. gossypiifolia. Vinte e cinco espécies de ácaros foram encontradas associadas ao pinhão manso, pertencentes às famílias: Phytoseiidae, Tetranychidae, Tarsonemidae, Tenuipalpidae, Winterschmidtiidae, Iolinidae, Cryptognathidae, Cunaxidae e Ascidae. Duas delas têm potencial para se tornarem pragas: Polyphagotarsonemus latus (Heterostigmata: Tarsonemidae) e Tetranychus bastosi (Prostigmata: Tetranychidae).

Palavras-chave: Jatropha spp. Levantamento faunístico. Ácaros plantícolas. 


\section{Introdução}

O gênero Jatropha (Euphorbiaceae) possui mais de 70 espécies, incluindo $\mathrm{J}$. curcas L., J. gossypiifolia L. e J. mollissima Muell. Arg., que produzem sementes com conteúdos elevados de óleo. Estas espécies são nativas dos trópicos sul-americanos, especialmente no Brasil, porém são encontradas e utilizadas de várias maneiras na maioria das regiões tropicais e subtropicais do mundo (OPENSHAW, 2000).

Até a segunda Guerra Mundial, o principal emprego do óleo de pinhão manso (Jatropha curcas L.: Euphorbiaceae) era na saboaria. No entanto, devido às necessidades militares, outras possíveis utilizações começaram a ser estudadas. Como não pôde ser utilizado como lubrificante, devido a sua baixa viscosidade, pesquisas levaram a conclusão de que esse óleo poderia ser utilizado como combustível em motores a Diesel, o qual se comporta bem, sem qualquer tratamento prévio e com quase igual potência às conseguidas com Diesel derivado do petróleo (CORTESÃO, 1956; ARRUDA et al., 2004).

No Brasil, por ser uma planta existente de forma espontânea em áreas de solos pouco férteis e de clima desfavorável à maioria das culturas alimentares tradicionais, o pinhão manso, pode ser considerada uma das mais promissoras oleaginosas do sudeste, centro-oeste e nordeste, podendo substituir o diesel proveniente do petróleo (SANTOS et al., 2005). No entanto, existe uma grande carência de estudos sobre vários aspectos dessa planta em forma de cultivo. Apesar de ser relatado como resistente a pragas, o pinhão manso pode ser atacado pelo ácaro vermelho (Tetranychus bastosi Baker \& Sales: Tetranychidae), por tripes, percevejo fitófago 
(Pachicoris torridus), cigarrinha verde (Empoasca sp.) e cupins (SATURNINO, 2005), além do ácaro branco (Polyphagotarsonemus latus: Tarsonemidae) (SANTOS et al., 2005).

Jatropha gossypiifolia e J. mollissima são suas espécies de jatrofas bastante comuns nas regiões onde vem sendo estimulado o plantio de J. curcas, principalmente no nordeste brasileiro.

Jatropha gossypiifolia é denominada popularmente de diversas formas, mas mais comumente como pinhão roxo. Possui folhas e frutos com propriedades medicinais, com grande uso na medicina popular como agente antiinflamatório, anti-hipertensivo e anti-reumático entre outros (SANTOS et al., 2006). Pouco se conhece sobre a acarofauna associada a essa espécie, existindo apenas registros da espécie $T$. bastosi (TUTTLE et al., 1977; MORAES \& FLACHTMMAN, 1980).

Jatropha mollissima é uma espécie com distribuição ampla, ocorrendo em todos os estados do Nordeste do Brasil, exceto no Maranhão, habitando áreas de Caatinga e Restingas (GALLINDO, 1985). Não foram encontrados registros de ácaros associados a essa espécie na literatura.

Desse modo, o conhecimento da acarofauna associada a esses vegetais é de grande importância para estudos de manejo, tendo em vista que essas plantas podem servir como reservatório para ácaros fitófagos ou podem abrigar ácaros predadores, os quais podem funcionar como agentes de controle biológico de pragas de J. curcas. 


\section{Objetivo}

Esse trabalho teve como objetivo o levantamento das espécies de ácaros associadas às espécies J. curcas, J. gossypiifolia e J. mollissima (Euphorbiaceae), em Jales-SP, Itapagipe-MG e Nordeste do Brasil.

\section{Material e Métodos}

Foram realizadas coletas qualitativas em cultivos nos municípios de Jales-SP (dois pontos) e Itapagipe-MG (dois pontos), além de amostragens no norte de Minas Gerais e Nordeste do Brasil, em áreas cultivadas e silvestres (Figuras 1 e 2). Contudo, foram realizadas 71 amostragens em 24 municípios de seis estados (Tabela 1).

Para as coletas realizadas em Jales-SP e Itapagipe-MG, foram amostrados apenas indivíduos de $\mathrm{J}$. curcas. As folhas coletadas foram retiradas dos espécimes vegetais e acondicionadas em sacos de papel, que foram acomodados em caixas de isopor contendo gelo, para manter a temperatura baixa durante o transporte até 0 laboratório. No laboratório, as amostras foram mantidas em refrigerador até o momento da extração e montagem dos ácaros. A extração dos ácaros foi feita diretamente das folhas com o auxílio de um pincel de poucas cerdas sob microscópio estereoscópico. Já nas coletas no norte de Minas Gerais e nordeste, as folhas foram embebidas e lavadas em recipientes contendo etanol $60 \%$. O material de estudo foi acondicionado em potes de coleta devidamente etiquetados quanto à localização geográfica, sintomas aparentes e descrição da localidade do hospedeiro. 
Todos os ácaros encontrados foram montados em meio de Hoyer (FLECHTMMAN, 1975) em lâminas de microscopia e identificados com o auxílio de microscopia de luz com contraste de fases.

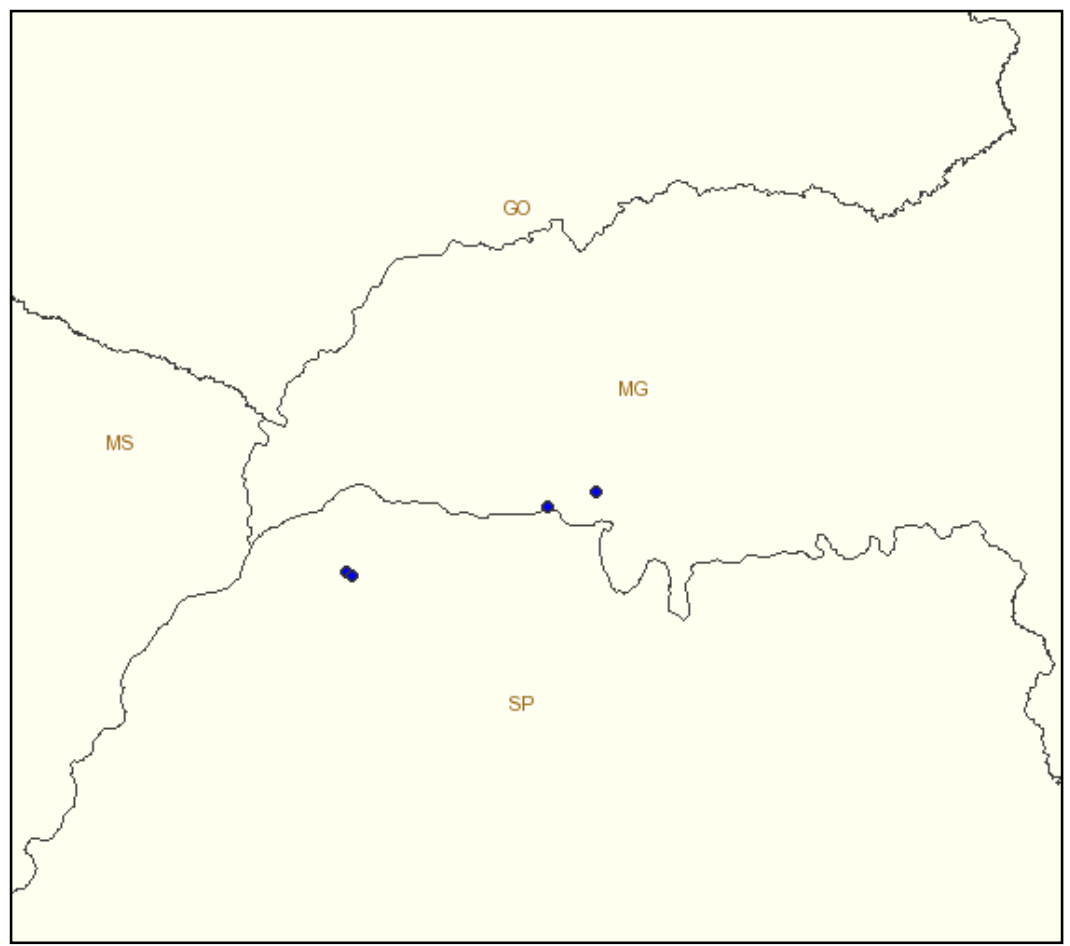

Figura 1 - Localização das áreas de coleta em exemplares de $J$. curcas nos municípios de Jales (SP) e Itapagipe (MG). 


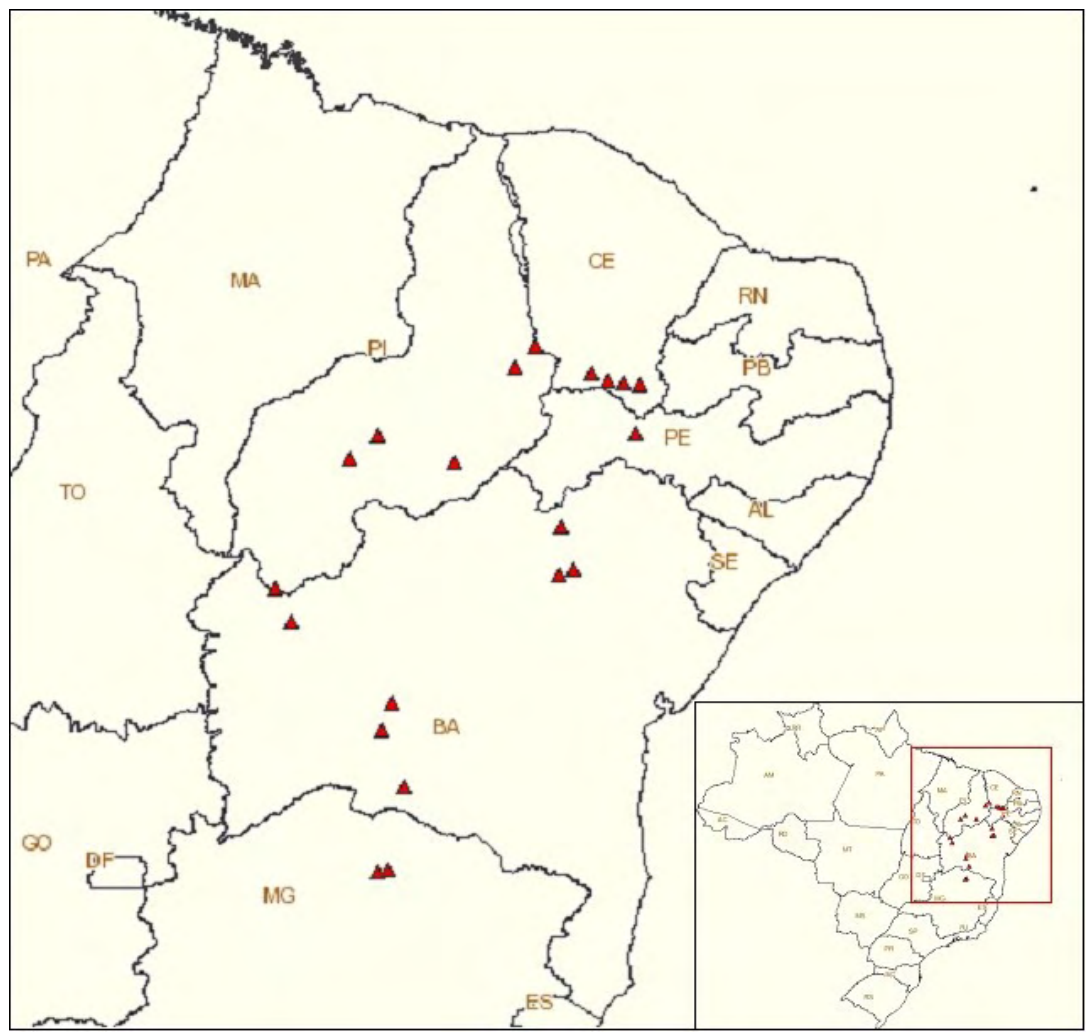

Figura 2 - Localização das áreas de coleta em exemplares do gênero Jatropha em municípios do norte de Minas Gerais e nordeste brasileiro.

Tabela 1. Localização das coletas em J. curcas, J. gossypiifolia e J. mollissima no Brasil.

\begin{tabular}{|c|c|c|}
\hline Localidade & Estado & Coordenadas \\
\hline Jales & $\mathrm{SP}$ & $\begin{array}{l}20^{\circ} 12^{\prime} \mathrm{S}, 50^{\circ} 32^{\prime} \mathrm{W} \\
20^{\circ} 13^{\prime} \mathrm{S}, 50^{\circ} 30^{\prime} \mathrm{W}\end{array}$ \\
\hline Itapagipe & MG & $\begin{array}{l}19^{\circ} 53^{\prime} \mathrm{S}, 49^{\circ} 33^{\prime} \mathrm{W} \\
19^{\circ} 49^{\prime} \mathrm{S}, 49^{\circ} 19^{\prime} \mathrm{W}\end{array}$ \\
\hline Nova Porteirinha & MG & $15^{\circ} 42^{\prime} \mathrm{S}, 43^{\circ} 18^{\prime} \mathrm{W}$ \\
\hline Janaúba & MG & $\begin{array}{l}15^{\circ} 43^{\prime} \mathrm{S}, 43^{\circ} 19^{\prime} \mathrm{W} \\
15^{\circ} 43^{\prime} \mathrm{S}, 43^{\circ} 18^{\prime} \mathrm{W} \\
15^{\circ} 43^{\prime} \mathrm{S}, 43^{\circ} 19^{\prime} \mathrm{W}\end{array}$ \\
\hline Palmas de Monte Alto & BA & $14^{\circ} 14^{\prime} \mathrm{S}, 43^{\circ} 03^{\prime} \mathrm{W}$ \\
\hline Paratinga & BA & $12^{\circ} 48^{\prime} \mathrm{S}, 43^{\circ} 12^{\prime} \mathrm{W}$ \\
\hline Santa Rita de Cássia & BA & $11^{\circ} 22^{\prime} \mathrm{S}, 4^{\circ} 55^{\prime} \mathrm{W}$ \\
\hline Antonio Gonçalves & BA & $10^{\circ} 33^{\prime} \mathrm{S}, 40^{\circ} 15^{\prime} \mathrm{W}$ \\
\hline Juazeiro & BA & $09^{\circ} 42^{\prime} \mathrm{S}, 40^{\circ} 22^{\prime} \mathrm{W}$ \\
\hline Senhor do Bonfim & BA & $10^{\circ} 27^{\prime} \mathrm{S}, 40^{\circ} 10^{\prime} \mathrm{W}$ \\
\hline Gurguéia & $\mathrm{PI}$ & $08^{\circ} 32^{\prime} \mathrm{S}, 43^{\circ} 56^{\prime} \mathrm{W}$ \\
\hline Divisa BA/PI & $\mathrm{BA} / \mathrm{PI}$ & $10^{\circ} 48^{\prime} \mathrm{S}, 45^{\circ} 09^{\prime} \mathrm{W}$ \\
\hline Bom Jesus da Lapa & PI & $13^{\circ} 15^{\prime} \mathrm{S}, 43^{\circ} 22^{\prime} \mathrm{W}$ \\
\hline Ibotirama & PI & $13^{\circ} 15^{\prime} \mathrm{S}, 43^{\circ} 22^{\prime} \mathrm{W}$ \\
\hline Canto do Buriti & PI & $08^{\circ} 08^{\prime} \mathrm{S}, 43^{\circ} 26^{\prime} \mathrm{W}$ \\
\hline São Raimundo Nonato & PI & $08^{\circ} 35^{\prime} \mathrm{S}, 42^{\circ} 09^{\prime} \mathrm{W}$ \\
\hline Divisa PI/CE & $\mathrm{PI} / \mathrm{CE}$ & $06^{\circ} 33^{\prime} \mathrm{S}, 40^{\circ} 48^{\prime} \mathrm{W}$ \\
\hline Nova Olinda & CE & $\begin{array}{l}07^{\circ} 10^{\prime} \mathrm{S}, 39^{\circ} 35^{\prime} \mathrm{W} \\
07^{\circ} 08^{\prime} \mathrm{S}, 39^{\circ} 38^{\prime} \mathrm{W}\end{array}$ \\
\hline Aratama & CE & $07^{\circ} 03^{\prime} \mathrm{S}, 39^{\circ} 51^{\prime} \mathrm{W}$ \\
\hline Juazeiro do Norte & CE & $07^{\circ} 12^{\prime} \mathrm{S}, 39^{\circ} 19^{\prime} \mathrm{W}$ \\
\hline Crato & CE & $07^{\circ} 14^{\prime} \mathrm{S}, 39^{\circ} 24^{\prime} \mathrm{W}$ \\
\hline Serra do Cariri & CE & $07^{\circ} 08^{\prime} \mathrm{S}, 39^{\circ} 38^{\prime} \mathrm{W}$ \\
\hline Salgueiro & PE & $08^{\circ} 05^{\prime} \mathrm{S}, 3^{\circ} 07^{\prime} \mathrm{W}$ \\
\hline
\end{tabular}




\section{Resultados}

Em J. curcas, foram coletados 14.139 ácaros representados por 25 espécies distribuídas por 10 famílias. A maior riqueza foi observada na família Phytoseiidae, que apresentou 8 gêneros e 11 espécies. Já o maior número de indivíduos coletados foi observado nas famílias Tarsonemidae, com 8.934 indivíduos, e Tetranychidae, com 1.801 ácaros.

As espécies mais constantes nas amostragens foram Euseius citrifolius Denmark \& Muma e Euseius concordis (CHANT).

Em Jatropha gossypiifolia (pinhão roxo), foram coletados: Euseius citrifolius (8); Pronematus sp. (13); Tetranychus bastosi (49) e Brevipalpus obovatus (6). Em Jatropha mollissima foram coletados: Tetranychus bastosi (61); Czenspinskia sp. (9) e Brevipalpus obovatus (1). 
Espécies de ácaros associadas à J. curcas, J. gossypiifolia e J. mollissima :

\section{ORDEM MESOSTIGMATA}

\section{PHYTOSEIIDAE}

\section{Euseius citrifolius Denmark \& Muma}

Euseius citrifolius Denmark \& Muma, 1970: 222; Moraes \& McMurtry, 1983: 138; Moraes et al., 1986: 38; 1991: 131; 2004: 64; Feres \& Moraes, 1998: 127; Gondim Jr. \& Moraes, 2001: 74; Zacarias \& Moraes, 2001: 580; Noronha \& Moraes, 2002: 1114; Chant \& McMurtry, 2005a: 215; Lofego et al., 2004: 4; Guanilo et al., 2008: 17; Lofego et al., 2009.

Material examinado: 693 fêmeas em J. curcas: Jales-SP; Itapagipe-MG; JanaúbaMG; Nova Porteirinha-MG; Divisa BA/PI; Juazeiro do Norte-CE; Guanambi-BA. 8 fêmeas em J. gossypiifolia: São Raimundo Nonato-PI. 


\section{Euseius concordis (Chant)}

Typhlodromus (Amblyseius) concordis Chant, 1959: 69.

Amblyseius (Iphiseius) concordis - Muma, 1961: 288.

Amblyseius concordis - Chant \& Baker, 1965: 22.

Euseius concordis - Denmark \& Muma, 1973: 264; Moraes \& Oliveira, 1982: 317;

Moraes \& McMurtry, 1983: 138; Moraes et al., 1986: 39; 2004: 64; Moraes \&

Mesa, 1988: 80; Feres \& Moraes, 1998: 127; Gondim Jr. \& Moraes, 2001: 74;

Noronha \& Moraes, 2002: 1116; Chant \& McMurtry, 2005a: 215; Lofego et al., 2004: 5; Guanilo et al., 2008a: 17; 2008b: 12.

Euseius flechtmanni Denmark \& Muma 1970: 223; 1973: 261 (Sinonímia de acordo com Moraes et al. 1982).

Material examinado: 280 fêmeas em J. curcas: Jales-SP; Itapagipe-MG; JanaúbaMG; Nova Porteirinha-MG; Fazenda Violetto-PI; Nova Olinda-CE.

\section{Ricoseius loxocheles (De Leon)}

Amblyseius (Ricoseius) De Leon, 1965

Ricoseius loxocheles - Denmark \& Muma, 1968; Denmark \& Muma, 1970:119;

Denmark \& Muma, 1973: 249; Lofego et al., 2004.

Material examinado: 99 fêmeas em J. curcas: Jales - SP. 


\section{Amblyseius aerialis (Muma)}

Amblyseiopsis aerialis Muma, 1955.

Typhlodromus (Amblyseius) aerialis - Chant, 1959: 88.

Amblyseius aerialis - Athias-Henriot, 1957: 338; DeLeon, 1966: 91; Moraes et al., 1986:

6, 1991: 117, 2004: 13; Moraes \& Mesa, 1988: 71; Denmark \& Muma, 1989: 15; Kreiter \& Moraes, 1997: 377; Feres \& Moraes, 1998: 126; Moraes et al., 1999 (2000): 238; Gondim Jr. \& Moraes, 2001: 67; Feres et al., 2005: 3. Buosi et al., 2006.

Material examinado: 4 fêmeas em J. curcas: Itapagipe-MG.

Amblyseius neochiapensis Lofego, Moraes \& McMurtry Amblyseius neochiapensis Lofego, Moraes \& McMurtry, 1999 (2000): 462.

Material examinado: 5 fêmeas em J. curcas: Jales-SP.

Amblyseius acalyphus Denmark \& Muma

Amblyseius acalyphus Denmark \& Muma, 1973: 242, 1989: 75; Moraes et al., 1986: 6;

Feres \& Moraes, 1998: 125; Feres et al., 2005.

Material examinado: 22 fêmeas em J. curcas: Itapagipe-MG. 


\section{Amblydromalus limonicus (Garman \& McGregor)}

Amblyseius limonicus Garman \& McGregor, 1956: 11; Moraes et al. 1994: 211.

Amblyseiopsis limonicus - Garman, 1958: 78.

Typhlodromus (Amblyseius) limonicus - Chant, 1959: 96.

Typhlodromus (Amblyseius) garmani.

Typhlodromalus limonicus - DeLeon, 1967: 22; Muma et al., 1970: 90.

Amblydromalus limonicus - Chant \& McMurtry, 2005: 203.

Material examinado: 2 fêmeas em J. curcas: Itapagipe-MG.

\section{Thyphodromalus aripo De Leon}

Typhlodromalus aripo De Leon, 1967: 21; Denmark \& Muma, 1973: 257; Moraes et al., 1986: 128, 1999 (2000): 252; 2004: 195; Feres \& Nunes, 2001: 1255; Lofego et al., 2004: 10; Feres et al., 2005: 4; Buosi et al., 2006: 10.

Amblyseius aripo - Moraes \& McMurtry, 1983: 132; Moraes \& Mesa, 1988: 73; Feres \& Moraes, 1998: 126.

Material examinado: 62 fêmeas em J. curcas: Jales-SP, Itapagipe-MG e Fazenda Violetto-PI. 


\section{Galendromus annectens (De Leon)}

Typhlodromus annectens De Leon, 1958: 75; Chant \& Yoshida-Saul, 1984: 1868;

Moraes \& McMurtry, 1983: 142; Moraes \& Mesa, 1988: 82; Moraes et al., 1991:

134; Feres \& Moraes, 1998: 128; Feres, 2000: 161; Feres \& Nunes, 2001: 1256;

Zacarias \& Moraes, 2001: 583.

Galendromus annectens - Muma, 1961: 298; 1963: 20; Muma et al., 1970: 135;

Denmark \& Muma, 1973: 274; Farias et al., 1981: 21; Denmark, 1982: 142;

Moraes et al., 1982: 21; 1986: 186; Gondim Jr. \& Moraes, 2001: 88; Ferla \& Moraes, 2002a: 1019; Feres et al., 2003: 375.

Galendromus (Galendromus) annectens - Moraes et al., 2004: 265; Lofego et al., 2004:

12; Feres et al., 2005: 4. Buosi et al., 2006.

Material examinado: 7 fêmeas em J. curcas: Jales-SP.

\section{Proprioseiops sp.}

Material examinado: 1 fêmea em J. curcas: Itapagipe-MG. 
Iphiseiodes zuluagai Denmark \& Muma

Iphiseiodes zuluagai Denmark \& Muma, 1972: 23; 1973: 251, 1975: 287; Moraes et al.,1982: 18, 1986: 61; 1999 (2000): 245; 2004: 91; Aponte \& McMurtry, 1995: 176; Kreiter \& Moraes, 1997: 377; Feres \& Moraes, 1998: 127; Feres \& Nunes, 2001: 1255; Feres et al., 2002: 140; 2005: 3; Gondim Jr. \& Moraes, 2001: 76; Zacarias \& Moraes, 2001: 581; Ferla \& Moraes, 2002: 1013; Lofego et al., 2004: 7; Buosi et al., 2006.

Amblyseius zuluagai - Moraes \& Mesa, 1988: 79; Moraes et al., 1991: 125.

Material examinado: 46 fêmeas em J. curcas: Jales-SP e Itapagipe-MG.

\section{ASCIDAE}

Asca sp.

Material examinado: 1 fêmea em J. curcas: Itapagipe-MG. 


\section{ORDEM PROSTIGMATA}

\section{TETRANYCHIDAE}

Tetranychus bastosi Tuttle, Baker \& Sales

Tetranychus bastosi Bolland, Gutierrez \& Flechtmann, 1998: 177.

Material examinado: 1.671 fêmeas e 12 machos em J. curcas: Jales-SP, ItapagipeMG, Divisa Piaui / Ceará, Nova Olinda-CE, Juazeiro do Norte-CE e Guanambi-BA; 47 fêmeas e 2 machos em J. gossypiifolia: São Raimundo Nonato-PI; 58 fêmeas e 3 machos em J. mollissima: Bom Jesus da Lapa / Ibotirama-PI, Salgueiro-PE, Juazeiro-BA.

\section{Oligonychus sp.}

Material examinado: 7 fêmeas em J. curcas: Jales-SP.

\section{Allonychus sp.}

Material examinado: 1 fêmea em J. curcas: Jales-SP. 


\section{TENUIPALPIDAE}

\section{Brevipalpus obovatus (Donnadieu)}

Brevipalpus obovatus Donnadieu, 1875: 116; Pritchard \& Baker, 1958: 231; De Leon, 1961a: 48; Baker, Tuttle \& Abbatiello, 1975: 18; Meyer, 1979: 86; Baker \& Tuttle, 1987: 96; Feres et al., 2005.

Brevipalpus pereger - Donnadieu, 1875: 116.

Tenuipalpus inornatus - Banks, 1912: 97.

Tenuipalpus bioculatus - McGregor, 1914: 354.

Tenuipalpus pseudocuneatus - Blanchard, 1940: 11.

Brevipalpus inornatus - Pritchard \& Baker, (1951) 1952: 36.

Material examinado: 125 fêmeas em J. curcas: Jales-SP, Itapagipe-MG, Janaúba-MG, Nova Porteirinha-MG, Fazenda Violetto-PI, Divisa do Piauí / Ceará e Guanambi-BA; 6 fêmeas em J. gossypiifolia: São Raimundo Nonato-PI; 1 fêmea em J. mollissima: Bom Jesus da Lapa / Ibotirama-PI.

\section{TYDEIDAE}

\section{Lorryia formosa Cooreman}

Lorryia formosa Cooreman,1958: 6-10; Baker, 1968: 995-996. Feres et al., 2005.

Material examinado: 40 fêmeas em J. curcas: Jales-SP e Itapagipe-MG. 


\section{IOLINIDAE}

\section{Pronematus sp.}

Material examinado: 153 fêmeas em J. curcas: Jales-SP e Itapagipe-MG; 13 fêmeas em J. gossypiifolia: São Raimundo Nonato.

\section{CUNAXIDAE}

\section{Cunaxoides sp.}

Material examinado: 1 fêmea em J. curcas: Itapagipe-MG.

\section{TARSONEMIDAE}

\section{Polyphagotarsonemus latus (Banks)}

Tarsonemus latus Banks, 1904: 1553.

Hemitarsonemus latus - Ewing, 1939: 54.

Neotarsonemus latus - Smiley, 1967: 137.

Polyphagotarsonemus latus - Beer \& Nucifora, 1965: 38; Feres, 2000: 164.

Material examinado: 8.932 fêmeas em J. curcas: Jales-SP, Itapagipe-MG, JanaúbaBA, Nova Porteirinha-MG e Fazenda Violetto-PI.

\section{Tarsonemus sp.}

Material examinado: 1 fêmea em J. curcas: Jales-SP. 
Xenotarsonemus sp.

Material examinado: 1 fêmea em J. curcas: Itapagipe-MG.

\section{ORDEM ASTIGMATA}

\section{WINTERSCHMIDTIIDAE}

\section{Czenspinskia sp.}

Material examinado: 1.822 fêmeas em J. curcas: Jales-SP, Itapagipe-MG, Nova Porteirinha-MG, Fazenda Violetto-PI, Divisa do Piauí / Ceará e Eliseu Martins-PI.

\section{Oulenzia sp.}

Material examinado: 12 fêmeas em J. curcas: Jales-SP e Itapagipe-MG.

\section{CRYPTOGNATHIDAE}

\section{Cryptognathus sp.}

Material examinado: 1 fêmea em J. curcas: Itapagipe-MG. 


\section{Discussão}

Euseius citrifolius e E. concordis (Phytoseiidae) são comumente registradas em outras euforbiáceas no estado de São Paulo, principalmente Havea brasiliensis (FERES et al., 2002; HERNANDES \& FERES, 2006; DEMITE \& FERES 2007; BELLINI et al., 2008) e Mabea fistulifera (FERES \& MORAES, 1998; DAUD \& FERES, 2004; DAUD \& FERES, 2005). Ambas as espécies são consideradas predadoras generalistas, porém, com preferência alimentar por pólen (McMURTRY \& CROFT, 1997).

As nove espécies restantes de fitoseídeos somam apenas $21 \%$ do total dessa família, sendo que, Ricoseius loxocheles (De Leon), representou 8\% do total. Em registros prévios dessa espécie no estado de São Paulo poucos indivíduos tem sido encontrados, de 1 a 3 (DENMARK \& MUMA, 1970; LOFEGO et al., 2004). Isso pode ser um indicativo que $J$. curcas pode possuir algum atrativo para essa espécie de ácaro, tendo em vista que foram amostrados 99 indivíduos nesse trabalho.

Ácaros fitófagos das famílias Tarsonemidae e Tetranychidae foram encontrados em grandes infestações. A grande abundância de ácaros fitófagos em um agroecossistema pode estar relacionada à baixa heterogeneidade ambiental e a grande disponibilidade de alimento, como é o caso de um monocultivo (BELLINI et al., 2005). Em agroecossistemas, espécies fitófagas têm maiores possibilidades de atingir grandes níveis populacionais devido à menor diversidade de inimigos naturais (ALTIERI et al. 2003).

As espécies Polyphagotarsonemus latus Banks (Tarsonemidae) e Tetranychus bastosi Tuttle, Baker \& Sales (Tetranychidae) compreenderam quase que em totalidade 
do número de indivíduos coletados em suas famílias. Ambas as espécies já haviam sido relatadas em J. curcas no Brasil (ALBUQUERQUE et al., 2006; SANTOS et al., 2006).

O ácaro branco, $P$. latus, foi observado em grandes infestações em alguns exemplares de pinhão manso durante o estudo, principalmente em folhas jovens, provocando o enrugamento das folhas e diminuição do desenvolvimento normal da planta. Dias et al. (2007), considera o ácaro branco como a maior praga para a cultura de pinhão manso no Brasil.

Existem relatos de Tetranychus bastosi em espécies vegetais da família Euphorbiaceae como Ricinus comunis, Manihot pseudoglaziovii, Jatropha gossypiifolia além de espécies pertencentes a outras famílias (MORAES \& FLECHTMANN, 1981). No Brasil, os relatos desse ácaro em pinhão manso limitam-se a região nordeste e, a presença desse ácaro no estado de São Paulo é um indicativo de que T. bastosi possui uma distribuição mais ampla.

Tetranychus bastosi foi coletado em grandes infestações em alguns indivíduos, aparentemente prejudicando seu desenvolvimento. As plantas infestadas geralmente eram menores que as não infestadas e apresentavam folhas amareladas com presença de pontos brancos.

Para Santos et al. (2006), T. bastosi é uma praga em potencial para a cultura do pinhão. Com isso, a presença desse ácaro em áreas experimentais em São Paulo reforça a necessidade de mais estudos sobre a comunidade acarina nessa espécie vegetal. 
Tendo em vista a presença dos ácaros fitófagos $T$. bastosi e $B$. obovatus nos hospedeiros $\mathrm{J}$. gossypiifolia e J. mollissima, não é aconselhável manter esses vegetais nas proximidades de lavouras de pinhão manso até que mais estudos sejam feitos para avaliar a função dessas plantas como reservatório ou não para essas espécies de ácaros. 


\section{Referências}

ALBUQUERQUE, F. A. ; OLIVEIRA, J. M. C. ; BELTRAO, N. M. E. ; SILVA, J. C. A. ; SOUSA, M. F. ; VALE, D. G. 2006. Ocorrência do ácaro Polyphagotarsonemus latus Banks (Acari: Tarsonemidae) sobre plantas de pinhão manso, Jatropha curcas L., (Euphorbiaceae), no Estado da Paraíba. 2o Congresso Brasileiro de Mamona, Sergipe. $2^{\circ}$ Congresso Brasileiro de Mamona - Cenário atual e perspectivas.

ALTIERI, M.A.; SILVA, N.E.; NICHOLLS C.I. 2003. O papel da biodiversidade no manejo de pragas. Ribeirão Preto, Editora Holos Ltda, 226p.

APONTE, O.; MCMURTRY, J.A. 1995. Revision of the genus Iphiseiodes DeLeon (Acari: Phytoseiidae). International Journal of Acarology, 21, 165-183.

ARRUdA, F. P; BELTRÃO, M. N. E; ANDRADE, A. P; PEREIRA, W. E; SEVERINO, L. S. 2004. Cultivo de pinhão manso (Jatropha curca L.) como alternativa para o semiárido nordestino. Rev. bras. ol. fibros., Campina Grande, v.8, n.1, p.789-799.

BAKER, E.W. 1968. The genus Lorryia. Ann. Entomol. Soc. Am. 61:986-1008.

BAKER, E.W.; TUTTLE, D.M. 1987. The false spider mites of Mexico (Tenuipalpidae: Acari). Tech. Bull. / U.S. Dep. Agric. 1706:1-237.

BAKER, E.W.; TUTTLE, D.M.; ABBATIELLO, M.J. 1975. The false spider mites of northwestern and north central Mexico (Acarina:Tenuipalpidae). Smith. Contrib. Zool. 194:1-23.

BANKS, N. 1904. Class III, Arachnida, Order I, Acarina, four new species of injurious mites. Jour. N.Y. Entomol. Soc. 12:53-56.

BANKS, N. 1912. New american mites. Proc. Entomol. Soc. Wash. 14: 96-98.

BEER, R.E; NUCIFORA, A. 1965. Revisione dei generi della famiglia Tarsonemidae (Acarina). Boll. Zool. Agric. Bachic. Ser. 2. 7:19-43.

BELLINE, M. R., MORAES, G. J. \& FERES, R. J. F. 2005. Plantas de ocorrência espontânea como substratos alternativos para fitoseídeos (Acari: Phytoseiidae) em cultivos de seringueira Hevea brasiliensis Muell. Arg.(Euphorbiaceae), 22: 35-42. 
BELLINI, M. R; FERES, R. J. F.; BUOSI, R. 2008. Ácaros (Acari) de seringueira (Hevea brasiliensis, Euphorbiaceae) e de euforbiáceas espontâneas no interior dos cultivos. Neotropical Entomology, v. 37, p. 463-471.

BLANCHARD, E. 1940. Tres acaros daninos para los cultivos argentinos. Rev. Fac. Agron. La Plata (terepoca) 24: 11-18.

BUOSI, R., FERES, R.J.F., OLIVEIRA, A.R., LOFEGO, A.C. \& HERNANDES, F.A. 2006. Ácaros plantícolas (Acari) da "Estação Ecológica de Paulo de Faria", Estado de São Paulo, Brasil. Biota Neotropica, 6, 1-20.

CHANT, D.A.; MCMURTRY, J.A. 2005. A review of the subfamily Amblyseiinae Muma (Acari: Phytoseiidae): Part VI. The tribe Euseiini n. tribe, subtribes Typhlodromalina n. subtribe, Euseiina n. subtribe, and Ricoseiina n. subtribe. International Journal of Acarology, 31, 187-224.

COOREMAN, J. 1958. Notes et observations sur les Acariens. VII- Photia graeca n.sp. (Acaridia, Canestriniidae) et Lorryia formosa n. sp. (Stomatostigmata, Tydeydae). Bull. Inst. R. Sci. Nat. Belg. Sci. Entomol. 34:1-10.

CORTESÃO, M. Culturas tropicais: plantas oleaginosas. Lisboa: Clássica, 1956. 231p.

DAUD, R. D.; FERES, R. J. F. 2004. O valor de Mabea fistulifera Mart. (Euphorbiaceae), planta nativa do Brasil, como reservatório para o predador Euseius citrifolius Denmark \& Muma (Acari, Phytoseiidae). Revista Brasileira de Zoologia, Curitiba, v. 21, n. 3, p. 453-458.

DAUD, R. D.; FERES, R. J. F. 2005. Diversidade e flutuação populacional de ácaros (Acari, Arachnida) em Mabea fistulifera Mart. (Euphorbiaceae) de dois fragmentos de Mata Estacional Semidecídua em São José do Rio Preto, São Paulo, Brasil. Neotropical Entomology, Londrina, v. 34, n. 2, p. 191-201.

DELEON, D. 1961. Eight new Amblyseius from Mexico with collection notes on two other species (Acarina: Phytoseiidae). The Florida Entomologist, 44, 85-91.

DELEON, D. 1966. Phytoseiidae of British Guyana with keys to species (Acarina: Mesostigmata). Studies the Fauna

of Suriname and other Guyanas, 8: 81-102. 
DEMITE, P.R.; FERES R.J.F. 2005. Influência de Vegetação Vizinha na Distribuição de Ácaros em Seringal (Hevea brasiliensis Muell. Arg., Euphorbiaceae) em São José do Rio Preto, SP. Neotropical Entomology. 34:829-986.

DEMITE, P.R; FERES, R. J. F. 2007. Ocorrência e flutuação populacional de ácaros (Acari) associados a seringais (Hevea brasiliensis Muell. Arg.) vizinhos de fragmentos de cerrado. Neotropical Entomology, Londrina, v. 36, p. 117-127.

DENMARK, H.A; MUMA, M.H. 1970. Some phytoseiid mites of Paraguay (Phytoseiidae: Acarina). The Florida Entomologist, 53, 219-227.

DIAS, L.A. dos S.; LEME, L.P.; LAVIOLA, B.G; PALLINI, A.; PEREIRA, O.L.; DIAS, D.C.F.S.; CARVALHO, M.; MANFIO, C.E.; SANTOS,A.S dos; SOUSA, L.C.A.; OLIVEIRA, T.S. de; PRETTI, L.A. 2007. Cultivo de pinhão manso (Jatropha curcas L.): para produção de óleo combustível, Viçosa, Editora UFV, 40p.

DONNADIEU, A.L. 1875. Recherches pour servir à I'historie dês Tétranyques. Ann. Soc. Lyon. 12:1-134.

EWING, H. E. 1939. A revision of the mites of the subfamily Tarsoneminae of North America, the West Indies and Hawaiian Islands. Tech. Bull. / U.S. Dep. Agric. (653):1-63.

FERES, R. J.F; MORAES, G.J. 1998. Phytoseiid mites (Acari: Phytoseiidae) from wood areas in the State of São Paulo, Brazil. Systematic and Applied Acarology, 3, 125132.

FERES, R.J.F. 2000. Levantamento e observações naturalísticas da acarofauna (Acari, Arachnida) de seringueiras cultivadas (Hevea spp., Euphorbiaceae) no Brasil. Rev. Bras. Zool. 17: 157-173.

FERES, R.J.F; NUNES, M.A. 2001. Ácaros (Acari, Arachnida) associados a euforbiáceas nativas em áreas de cultivo de seringueiras (Hevea brasiliensis Muell. Arg., Euphorbiaceae) na região noroeste do Estado de São Paulo, Brasil. Rev. Bras. Zool. 18:1253-1264.

FERES, R.J.F.; ROSSA-FERES, D. C; DAUD, R.D; SANTOS, R.S. 2002. Diversidade de ácaros (Acari, Arachnida) em seringueiras (Hevea brasiliensis Muell. Arg.) na Região Noroeste do estado de São Paulo, Brasil. Rev. Bras. Zool. 19: 137-144. 
FERES, R.J.F.; LOFEGO, A.C; OLIVEIRA, A.R. 2005. Ácaros plantícolas (Acari) da "Estação Ecológica do Noroeste Paulista", Estado de São Paulo, Brasil. Biota Neotropica, 5, 1-14.

FERLA, N.J; MORAES, G.J. 2002. Ácaros (Arachnida, Acari) da seringueira (Hevea brasiliensis Muell. Arg.) no Estado do Mato Grosso, Brasil. Rev. Bras. Zool. 19:867888.

GALLINDO, F. 1985. O gênero Jatropha L. para Pernambuco. Dissertação de mestrado, Universidade Federal Rural de Pernambuco, Recife.

GONDIM Jr.; M.G.C.; MORAES, G.J. 2001. Phytoseiid mites (Acari: Phytoseiidae) associated with palm trees (Arecaceae) in Brazil. Systematic and Applied Acarology, $6,65-94$.

GUANILO, A.D.; MORAES, G.J; KNAPP, M. 2008. Phytoseiid mites (Acari: Phytoseiidae) of the subfamily Amblyseiinae Muma from Peru, with description of four new species. Zootaxa, 1880, 1-47.

HERNANDES, F. A.; FERES, R. J. F.; NOMURA, F. 2006. Biological cycle of Lorryia formosa Acari, Tydeidae) on rubber tree leaves: a case of thelytoky. Experimental and Applied Acarology, 38:237-242.

KREITER, S; MORAES, G.J. 1997. Phytoseiid mites (Acari: Phytoseiidae) from Guadeloupe and Martinique. Florida Entomologist, 80, 376-382.

LOFEGO, A.C; MORAES, G.J; Castro, L.A.S. 2004. Phytoseiid mites (Acari: Phytoseiidae) on Myrtaceae in the State of São Paulo, Brazil. Zootaxa. 516:1-18.

LOFEGO, A. C.; DEMITE, P. R.; KISHIMOTO, R. G.; MORAES, G. J. 2009. Phytoseiid mites on grasses in Brazil (Acari: Phytoseiidae). Zootaxa 2240: 41-59.

MCGREGOR, E.A. 1914. Four new tetranychids. Ann. Entomol. Soc. Am. 7: 354-364.

MCMURTRY, J.A. 1983. Phytoseiid mites from Guatemala, with description of two new species and redefinition of the genera Euseius, Typhlodromus and the Typhlodromus occidentalis species group (Acari: Mesostigmata). International Journal of Acarology, 25, 249-272. 
MCMURTRY, J.A; CROFT, B.A. 1997. Life-styles of phytoseiid mites and their roles in biological control. Annual Review of Entomology, Palo Alto, 42: 291-321.

MEYER, M.K.P.S. 1979. The Tenuipalpidae (Acari) of Africa with keys to the world fauna. Entomology Mem. Dep. agric. tech. Serv. Repub. S. Afr. 50:1-135.

MORAES, G.J; FLECHTMANN, C.H.W. 1980. Paralelo entre dois complexos Euphorbiaceae - Tetranychidae (Acari) no Nordeste e sudeste do Brasil. Anais da ESALQ. Piracicaba, 37:743-745.

MORAES, G. J; FLECHTMANN, C.H.W. 1981. Ácaros fitófagos do Nordeste do Brasil. Pesquisa Agropecuária Brasileira, Brasília,16:177-186.

MORAES, G.J; DENMARK, H.A; GUERRERO, J.M. 1982. Phytoseiidae mites of Colombia (Acarina: Phytoseiidae). International Journal of Acarology, 8, 15-22.

MORAES, G.J; MCMURTRY, J.A. 1983. Phytoseiid mites (Acarina) of northeastern Brazil with descriptions of four new species. International Journal of Acaroloy, 9, 131-148.

MORAES, G.J; MCMURTRY, J.A; DENMARK, H.A. 1986. A catalog of the mite family Phytoseiidae: references to taxonomy, synonymy, distribution and habitat. EmbrapaDDT, Brazil, 356pp.

MORAES, G.J; MESA, N.C. 1988. Mites of the family Phytoseiidae (Acari) in Colombia, with descriptions of three new species. International Journal of Acarology, 14, 71-88.

MORAES, G.J. de, KREITER, S. \& LOFEGO, A.C. 2000 (1999). Plant mites (Acari) of the French Antilles. 3. Phytoseiidae (Gamasida). Acarologia, 40, 237-264.

NORONHA, A.C. da S. \& MORAES, G.J. de. 2002. Variações morfológicas intra e interpopulacionais de Euseius citrifolius Denmark \& Muma e Euseius concordis (Chant) (Acari, Phytoseiidae). Revista Brasileira de Zoologia, 19, 1111-1122.

OPENSHAW, K. 2000. A review of Jatropha curcas: an oil plant of unfulfilled promise. Biomass and Bioenergy, v.19.

PRITCHARD, A.E; BAKER, E.W. (1951) 1952. The false spider mites of California (Acarina: Phytoptipalpidae). Univ. Calif. Publ. Entomol. 9 (1): 1-94.

PRITCHARD, A.E; BAKER, E.W. 1958. The false spider mites (Acarina: Tenuipalpidae). Univ. Calif. Publ. Entomol. 14:175-274. 
SANTOS, H. S; CARVALHO, S. V. A; BOARI, A. J; RIBEIRO, G. T; NAVIA, D. 2006. O ácaro Tetranychus bastosi TUTTLE, BAKER \& SALES (Prostigmata: Tetranychidae) infestando germoplasma nativo de Jatropha sp. no Estado do Sergipe, Brasil. 2o Congresso Brasileiro de Mamona, Sergipe. $2^{\circ}$ Congresso Brasileiro de Mamona Cenário atual e perspectivas.

SANTOS, M. S. F; CZECZKO, N. G; NASSIF, P. A. N; RIBAS-FILHO, J. M; ALENCAR, B. L. F; MALAFAIA, O; RIBAS, C. A. P. M; TRAUTWEIN, V. M; HENRIQUES, G. S; MAIA, J. M. A; BITTENCOURT, R. C. A. 2006. Avaliação do uso do extrato bruto de Jatropha gossypiifolia $L$. na cicatrização de feridas cutâneas em ratos. Acta Cirúrgica Brasileira - Vol 21.

SATURNINO, H. M.; PACHECO, D. D.; KAKIDA, J.; TOMINAGA, N.; GONÇALVES, N.P. 2005. Cultura do pinhão-manso (Jatropha curcas L.). Informe Agropecuário, v. 26, p.44-78.

SMILEY, R.L. 1967. Some Tarsonemidae of the Republic of the Congo (Acarina). Proc. Entomol. Soc. Wash. 66:145-150.

ZACARIAS, M.S. \& MORAES, G.J. de. 2001. Phytoseiid mite (Acari) associated with rubber tree and other euphorbiaceous plants in southeastern Brazil. Neotropical Entomology, 30, 579-586. 
Capítulo II. Ocorrência sazonal da acarofauna em cultivos de Jatropha curcas L. (Euphorbiaceae) em Jales-SP e Itapagipe-MG e a influência da vegetação espontânea na composição da comunidade.

\section{Rodrigo Luiz Costa Verona}


Abstract: There are a few studies about mite fauna in Jatropha curcas (Euphorbiaceae), restricted only to the records of potential pests as Polyphagotarsonemus latus (Heterostigmata: Tarsonemidae) and Tetranychus bastosi (Prostigmata: Tetranychidae). Thus, this study verified the seasonal occurrence mites in four crops of $J$. curcas in Jales-SP and Itapagipe-MG and evaluated the background vegetation's influence in the composition of mite community. Monthly collections were done in May 2008 to April 2009 in two crops at Jales-SP and two at Itapagipe-MG. In the same way was done another experiment at Itapagipe that evaluated two areas with different kind of crops: an area free of background vegetation and another, where this type of vegetation grew freely. In the study of seasonality were collected 11.308 mites, distributed in 16 species of 6 families. The family Phytoseiidae presented greater richness, 8 species, already the largest abundance has been observed in families Tarsonemidae and Tetranychidae. The floating population occurred differently in each crop studied and was observed a correlation of $P$. latus (Tarsonemidae) with the rainy season in one crop. Mites predators as E. citrifolius and Pronematus sp., were observed in greater abundance during the dry season, while phytophagous mites were observed in times of moderate rainfall ( $T$. bastosi) or during the rainy season ( $P$. latus). In the experiment with background vegetation were found 2.005 mites distributed in five families: Phytoseiidae, Iolinidae, Tarsonemidae, Tenuipalpidae and Winterschmidtiidae. The families Phytoseiidae and Iolinidae, possible predators, were more abundant in the presence of background vegetation than in the area without this type of vegetation.

Key words: Jatropha curcas. Seazonal distribution. Background vegetation. Acari community composition. 
Resumo: Existem poucos estudos sobre a acarofauna em J. curcas, restritos apenas à registros de possíveis pragas como Polyphagotarsonemus latus (Heterostigmata: Tarsonemidae) e Tetranychus bastosi (Prostigmata: Tetranychidae). Desse modo, esse estudo teve o objetivo de verificar a ocorrência sazonal de ácaros em quatro lavouras de pinhão manso em Jales-SP e Itapagipe-MG e avaliar se a vegetação espontânea exerce influência na composição da comunidade acarina. Para isso foram realizadas coletas mensais de maio de 2008 a abril de 2009 em duas lavouras em Jales-SP e duas em Itapagipe-MG. Também foi feito um experimento em uma lavoura em Itapagipe onde foram avaliadas duas áreas com manejos diferentes: uma área livre de vegetação espontânea e outra, onde esse tipo de vegetação cresceu livremente. No estudo da sazonalidade foram coletados 11.308 ácaros, distribuídos em 16 espécies representantes de 6 famílias. A família Phytoseiidae apresentou a maior riqueza, 8 espécies, já a maior abundância foi observada nas famílias Tarsonemidae e Tetranychidae. A flutuação populacional ocorreu de maneira diferente em cada uma das lavouras estudadas e foi observada uma correlação de Polyphagotarsonemus latus (Tarsonemidae) com a estação chuvosa em uma das lavouras. Ácaros predadores como E. citrifolius e Pronematus sp., foram observados em maior abundância durante a estação seca, enquanto ácaros fitófagos foram observados em épocas de pluviosidade moderada (Tetranychus bastosi) ou então durante toda a estação chuvosa ( $P$. latus). No experimento com vegetação espontânea foram encontrados 2.005 ácaros, sendo esses, distribuídos em cinco famílias: Phytoseiidae, lolinidae, Tarsonemidae, Tenuipalpidae e Winterschmidtiidae. Os ácaros das famílias Phytoseiidae e lolinidae, possíveis predadores, foram mais abundantes na presença de vegetação espontânea do que na área sem esse tipo de vegetação.

Palavras-chave: Jatropha curcas. Distribuição sazonal. Vegetação espontânea. Composição da comunidade acarina. 


\section{Introdução}

Estudos têm demonstrado que a estrutura das comunidades de ácaros plantícolas varia conforme a época do ano (DAUD \& FERES, 2005; BELLINI et al., 2005a; LOFEGO \& MORAES 2006; DAUD \& FERES, 2007; DEMITE \& FERES, 2007). Em se tratando de cultivos agrícolas essas variações podem ter um efeito direto no manejo da cultura em questão, uma vez que, a maior incidência de ácaros fitófagos ou predadores pode interferir na produção.

Nas lavouras implantadas até o momento, o pinhão manso tem sofrido o ataque de várias pragas como ácaro vermelho, o ácaro branco, tripes, percevejos fitófagos (Pachicoris torridus), cigarrinha verde (Empoasca sp.) e cupins (DIAS et al., 2007). Por se tratar de uma cultura nova, ainda não existem estudos sobre as formas adequadas de manejo visando minimizar os danos causados por essas pragas. Um dos principais fatores na queda de produtividade em qualquer cultivo é o aparecimento de pragas e, são notáveis os problemas de importância econômica ocasionados por ácaros em plantas cultivadas (JEPPSON et al., 1975). A utilização de agrotóxicos sem o conhecimento de sua ação sobre inimigos naturais tem provocado sérios problemas em diversas culturas (SILVA \& OLIVEIRA, 2006). Surtos de pragas secundárias são alguns dos problemas enfrentados pelos produtores agrícolas (VAN de VRIE et al., 1972). Outro problema associado ao uso excessivo de agrotóxicos é o desenvolvimento de resistência a alguns acaricidas utilizados na cultura (OMOTO et al., 2000).

De acordo com Bellini et al. (2005b), algumas plantas de ocorrência espontânea podem ser reservatórios de ácaros em seringais (Hevea brasiliensis: Euphorbiaceae). Embora as vantagens no controle de pragas em sistemas onde existe mais de um tipo 
de planta hospedeira sejam pouco conhecidas, trabalhos experimentais sugerem benefícios nesse tipo de manejo (ALTIERI et al., 2003). Desse modo, a vegetação associada a um determinado cultivo pode influenciar o modo de colonização e a abundância de possíveis pragas e seus predadores.

Estudos sugerem que a vegetação de entorno vizinha a áreas de cultivo também pode influenciar a colonização de ácaros, tendo importância no manejo ecológico de pragas. Em estudos conduzidos com Hevea brasiliensis (Euphorbiaceae), Demite \& Feres (2005) registraram as menores abundâncias de ácaros fitófagos nas proximidades de áreas naturais, onde pode ocorrer o deslocamento de ácaros predadores da vegetação de entorno para o seringal.

Sendo assim, o conhecimento das épocas onde a abundância de ácaros fitófagos é maior e o manejo adequado das lavouras de pinhão manso pode auxiliar no controle das populações de possíveis pragas dessa cultura e tornar tal sistema sustentável.

\section{Objetivos}

Esse trabalho teve como objetivo analisar a ocorrência sazonal das espécies de ácaros em quatro áreas de cultivo de J. curcas em Jales - SP e Itapagipe - MG e a influência da vegetação espontânea na composição da comunidade acarina. 


\section{Material e métodos}

\section{Estudo da Sazonalidade}

Para o estudo da sazonalidade foram realizadas amostragens mensais durante o período de maio de 2008 a abril de 2009 em duas lavouras de J. curcas no município

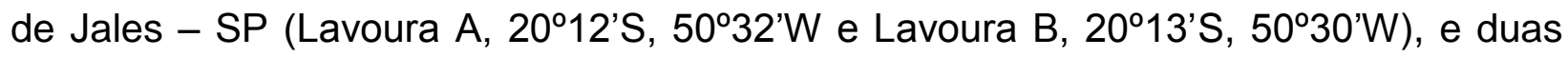
lavouras no município de Itapagipe - MG (Lavoura C 1953'S, 49³3’W e Lavoura D, $\left.19^{\circ} 49^{\prime} \mathrm{S}, 49^{\circ} 19^{\prime} \mathrm{W}\right)$, totalizando 12 coletas em cada lavoura. A lavoura "A" com aproximadamente 1,5 hectare, apresentava em seu entorno vários cultivos como manga, uva e quiabo, além de em uma de suas faces pasto. Plantas espontâneas foram observadas crescendo nas entrelinhas dessa lavoura. A lavoura "B" também com aproximados 1,5 hectare, apresentava em seu entorno culturas de laranja, café e pasto. Suas entrelinhas foram constantemente mantidas limpas por capinas. Esta foi a única lavoura onde foi feito uso de defensivos agrícolas (Enxofre). Na lavoura "C", com cerca de 2,5 hectáres, o entorno era constituído por um fragmento florestal, cana-deaçúcar e pastagem. Essa lavoura foi consorciada com milho e plantas espontâneas cresciam livremente nas entrelinhas. A lavoura "D", com aproximados 2,5 hectares, apresentava um entorno constituído exclusivamente por pasto e, plantas espontâneas estiveram presentes nas entrelinhas durante o trabalho.

Foram marcados dez indivíduos de $J$. curcas em cada lavoura, numerados de 1 a 10 da margem para o interior. Os indivíduos foram selecionados na linha central de cada lavoura de maneira intercalada. Foram coletadas 10 folhas de cada indivíduo, sendo cinco folhas dos ramos apicais, contendo folhas novas e cinco folhas basais, 
com folhagem média e grande. Desse modo, em cada coleta foram amostradas 100 folhas por lavoura e 400 folhas total/mês.

As folhas foram acondicionadas em sacos de papel individualizados e mantidos em caixa de isopor contendo gelo para o transporte até o Laboratório de Acarologia da Universidade Estadual Paulista - Ibilce/Unesp, campus de S. J. Rio Preto - SP.

Todas as folhas foram observadas em microscópio estereoscópico e os ácaros montados em lâminas de microscopia contendo meio de Hoyer (FLECHTMMAN, 1975). Após a montagem, as lâminas foram levadas a estufa $\left(56^{\circ} \mathrm{C}\right)$ e mantidas por 72 horas para a completa clarificação do material. Após a montagem, os ácaros foram identificados em microscopia de luz (contraste de fases) com auxílio de chaves dicotômicas específicas para cada família.

Após a retirada dos ácaros, as folhas de $J$. curcas foram desenhadas em papel sulfite (A4) para o cálculo da área foliar. Esses desenhos foram importados para o programa AutoCAD 2007 sob o formato DWF. Com o uso desse programa, as folhas foram redesenhadas digitalmente (comando PLINE) para calcular a área foliar (comando ÁREA). Desse modo, foi possível calcular a área foliar, área observada por indivíduo e área total por lavoura. Assim foi calculada a densidade para as espécies de maior importância agrícola, como fitófagas e predadoras. Desse modo, a ocorrência sazonal foi calculada para as espécies de ácaros mais abundantes e com registros em literatura de importância agrícola que compõe a comunidade em J. curcas. O índice de densidade foi estipulado em ácaros por $\mathrm{m}^{2}$ devido a baixa densidade encontrada para a maioria das famílias registradas, com exceção de Tarsonemidae e Tetranychidae. 
Os dados climáticos foram obtidos da Casa da Agricultura em Jales-SP e Martins (2009) para Itapagipe-MG.

\section{Experimento com modelos de manejo}

Para avaliar a influência da vegetação espontânea na comunidade acarina em lavouras de pinhão manso foi realizado um experimento na lavoura D. Nesta lavoura foi reservada uma área de aproximadamente $3.000 \mathrm{~m}^{2}$ mantida constantemente livre de vegetação espontânea através de capinas mensais. No restante da lavoura foi permitido o desenvolvimento de plantas espontâneas. Todas as plantas da lavoura, de ambas as áreas, eram da mesma idade e estavam submetidas às mesmas condições de solo e adubação. Não foi feito uso de nenhum tipo de agrotóxico na lavoura experimental.

Foram escolhidos 20 indivíduos de J. curcas da área limpa e 20 da área com vegetação para a realização de três amostragens quantitativas (fevereiro, abril e maio). Em cada coleta foram extraídas 10 folhas de cada indivíduo, sendo essas, amostradas de maneira aleatória.

O transporte do material, a montagem e identificação e a obtenção da área foliar segue a mesma metodologia descrita anteriormente.

Os ácaros das famílias Phytoseiidae e lolinidae foram tratados como predadores nesse trabalho. No entanto, há que se ressaltar que em muitos casos esses ácaros têm hábito alimentar diversificado (GERSON et al., 2003). Membros das famílias Tydeidae, Tenuipalpidae e Tetranychidae e o tarsonemideos Polyphagotarsonemus latus são 
fitófagos, já os ácaros da família Winterschmidtiidae encontrados nesse trabalho e o tarsonemideo Tarsonemus sp. foram tratados como micófagos (MORAES \& FLACHTMANN, 2008).

\section{Análises estatísticas}

Foram realizados os testes de diversidade Shannon-Wiener (Biodiversity 5.0) para estimar a diversidade amostrada nas lavouras e testes de regressão múltipla (Statistica 7.0) para avaliar se existe alguma relação entre as espécies de ácaros mais abundantes em cada lavoura e sua relação com os índices pluviométricos. Também foram realizados testes - t (Statistica 7.0) a fim de avaliar se existe diferença estatística entre as comunidades de ácaros registradas nos dois modelos de manejo na lavoura experimental.

\section{Resultados}

Foram coletados 11.308 ácaros nas amostragens mensais para o estudo de sazonalidade, sendo registradas 16 espécies representantes de 7 famílias: Phytoseiidae (8 espécies); Tetranychidae (2 espécies); Tarsonemidae (2 espécie); lolinidae (1 espécies); Tydeidae ( 1 espécie); Winterschmidtiidae (1 espécie) e Tenuipalpidae (1 espécie). As espécies com maior abundância foram Polyphagotarsonemus latus Banks (Heterostigmata: Tarsonemidae) (8.459 indivíduos) seguida por Tetranychus bastosi Tuttle, Baker e Sales (Prostigmata: Tetranychidae) (1.651 indivíduos), ambas as espécies fitófagas. A maior riqueza foi observada dentro 
da família Phytoseiidae (6 gêneros e 8 espécies), sendo a de maior abundância Euseius citrifolius (453 indivíduos) (tabela 1).

Espécies de ácaros predadores, como E. citrifolius e Pronematus sp., apresentaram maiores picos de abundância durante o período seco (maio a setembro) (Figuras 1 e 5), enquanto as espécies fitófagas apresentaram seus maiores picos de infestação no início da estação chuvosa, T. bastosi (outubro e novembro) (Figura 3), ou então durante toda a estação chuvosa, $P$. latus (outubro à abril) (Figuras 3 e 6). A única espécie que apresentou correlação positiva com o índice pluviométrico foi $P$. latus $(p<0,01)$ (figura 7). Espécies como Ricoseius loxocheles e Brevipalpus obovatus apareceram esporadicamente, sendo o primeiro, apenas na lavoura B (Figura 2), no início da estação seca, e o segundo, apenas na lavoura C (Figura 4), com baixa densidade em ambos os períodos.

A maior abundância de ácaros foi registrada na lavoura B, em Jales - SP, com picos de infestação nos meses de outubro e novembro de 2008 e março e abril 2009 (figura 3), seguida pela lavoura D, em Itapagipe - MG, com picos de infestação nos meses de dezembro 2008, janeiro 2009 e março de 2009 (figura 6). As duas lavouras restantes, A em Jales - SP (figura 1 e 2) e C em Itapagipe - MG (figura 4) não apresentaram abundância tão elevada. Apesar disso, os maiores índices de diversidade foram observados nessas lavouras $(A$ e $C), H^{\prime}=0,56$ e 0,55 respectivamente, enquanto para as lavouras $B$ e $D$ os índices foram $H^{\prime}=0,29$ e 0,07 respectivamente (tabela 2 ).

Isso pode ser mais bem compreendido quando observadas as curvas de componente de dominância (Figura 8). Na lavoura A, a curva de dominância foi 
composta por um ácaro predador tipo IV (generalista com preferência alimentar por pólen), seguida por duas espécies fitófagas e uma micófaga. Na lavoura C, uma espécie micófaga foi a mais abundante, seguida por duas espécies de ácaros predadores e então, uma espécie fitófaga. Já na lavoura B foi observado um grande efeito de dominância pela espécie fitófaga $P$. latus seguida por $T$. bastosi, assim como na lavoura $\mathrm{D}$, onde $P$. latus também exerceu grande dominância sobre as demais espécies.

No estudo referente à influência da vegetação espontânea sobre a composição da comunidade acarina em $\mathrm{J}$. curcas, foram coletados 2.005 ácaros distribuídos em 8 espécies de cinco famílias: Phytoseiidae, representada pelas espécies Euseius citrifolius (139), Iphiseiodes zuluagai (1), Thyphlodromalus aripo (39) e Amblyseius acalyphus (20); Tarsonemidae, (433 indivíduos) sendo todos representados pela espécie Polyphagotarsonemus latus; Tenuipalpidae (15 indivíduos), todos da espécie Brevipalpus obovatus; Iolinidae (10 indivíduos), todos Pronematus sp. e Winterschmidtiidae (1.348 indivíduos), todos Czenspinskia sp. (tabela 3). As análises estatísticas considerando apenas a comunidade de ácaros predadores indicaram diferença estatística entre a composição da comunidade sob os dois modelos de manejo $(p=0,02)$, porém, não houve diferença entre as comunidades de ácaros fitófagos $(p=0,19)$. Considerando a comunidade acarina em geral (predadores e fitófagos), não foi constatada diferença significativa $(p=0,06)$ (figura 9).

Quanto à riqueza, a área com vegetação espontânea teve um índice de diversidade maior que a área limpa, sendo $\mathrm{H}^{\prime}=0,42$ e 0,36 respectivamente (Tabela 3). 
Tabela 1. Lista de espécies de ácaros coletadas em Itapagipe MG e Jales SP, maio de 2008 à abril de 2009.

\begin{tabular}{lr}
\hline Família / Espécie & \\
\hline Phytoseiidae & Total de Indivíduos \\
Euseius citrifolius & 453 \\
Euseius concordis & 37 \\
Amblyseius neochiapensis & 5 \\
Amblyseius acalyphus & 2 \\
Galendromus annectens & 2 \\
Iphiseiodes zuluagai & 12 \\
Ricoseius loxocheles & 99 \\
Thyphlodromalus aripo & 27 \\
\hline Tetranychidae & \\
Tetranychus bastosi & \\
Olygonichus sp. & \\
\hline Tarsonemidae & \\
Polyphagotarsonemus latus & \\
Tarsonemus sp. & \\
Iolinidae & \\
Pronematus sp. & \\
Tydeidae & \\
Lorryia formosa & \\
\hline Winterschmidtiidae & \\
Czenspinskia sp. & \\
\hline Tenuipalpidae & \\
\hline Brevipalpus obovatus & \\
\hline & \\
\hline
\end{tabular}




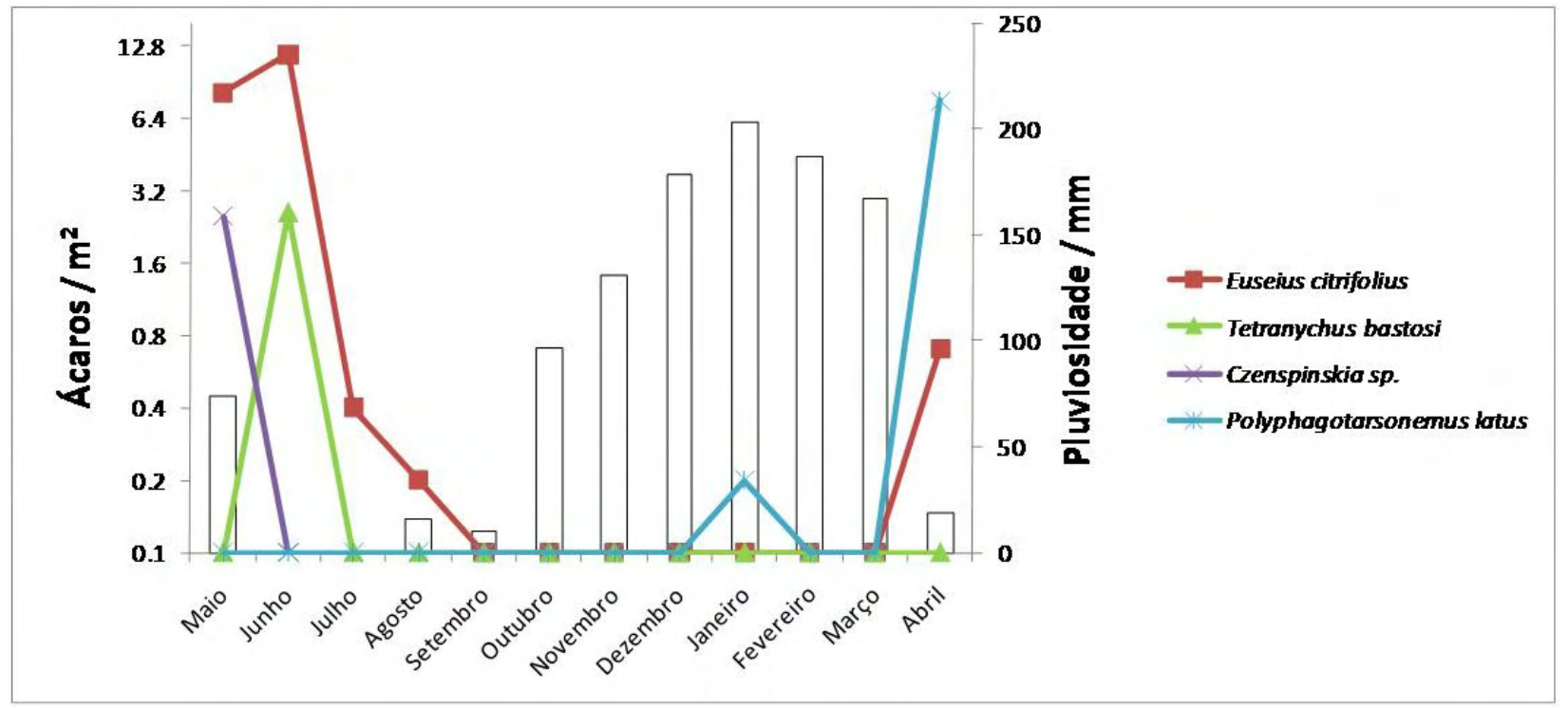

Figura 1. Ocorrência sazonal das espécies de ácaros mais abundantes em Jatropha curcas L. (Euphorbiaceae) na lavoura A, Jales - SP.

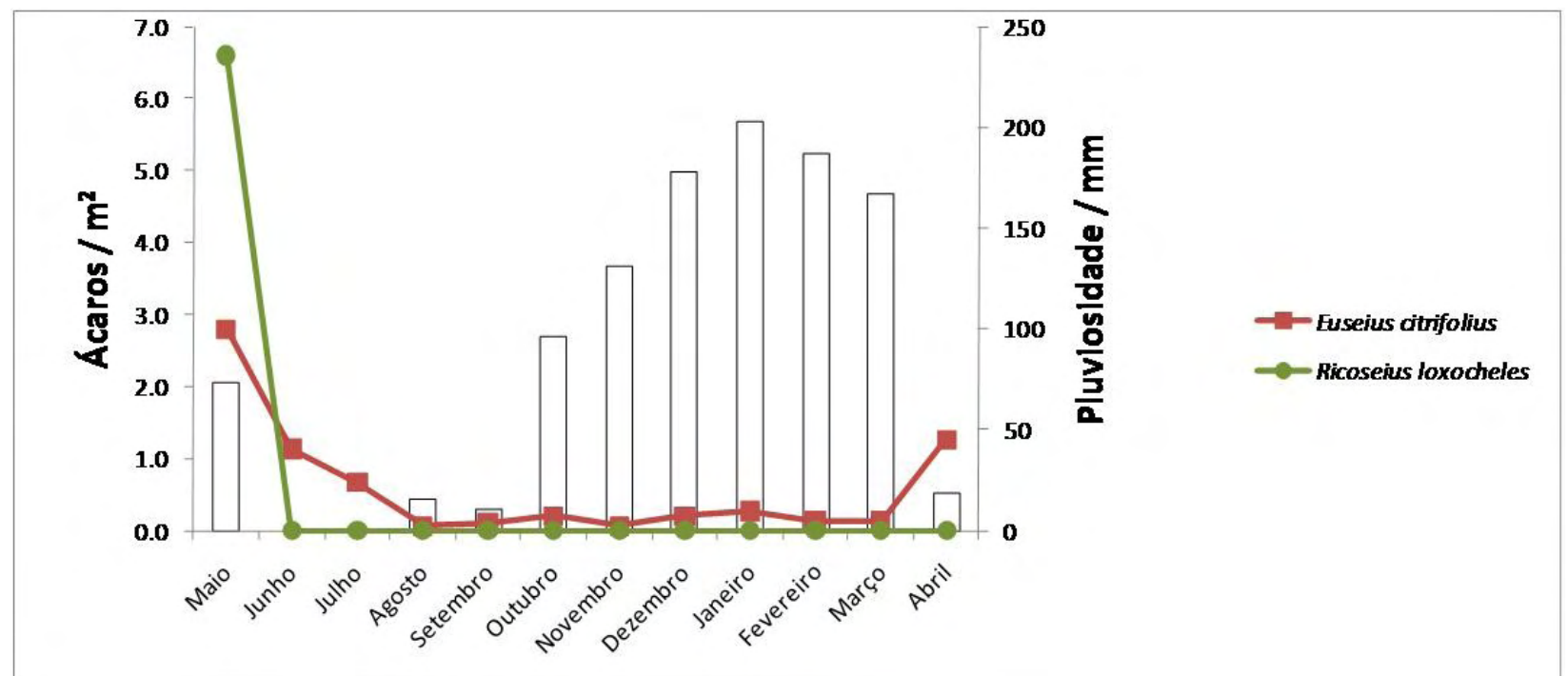

Figura 2. Ocorrência sazonal das espécies mais abundantes de fitoseídeos em J. curcas L. (Euphorbiaceae) na lavoura B, Jales - SP. 


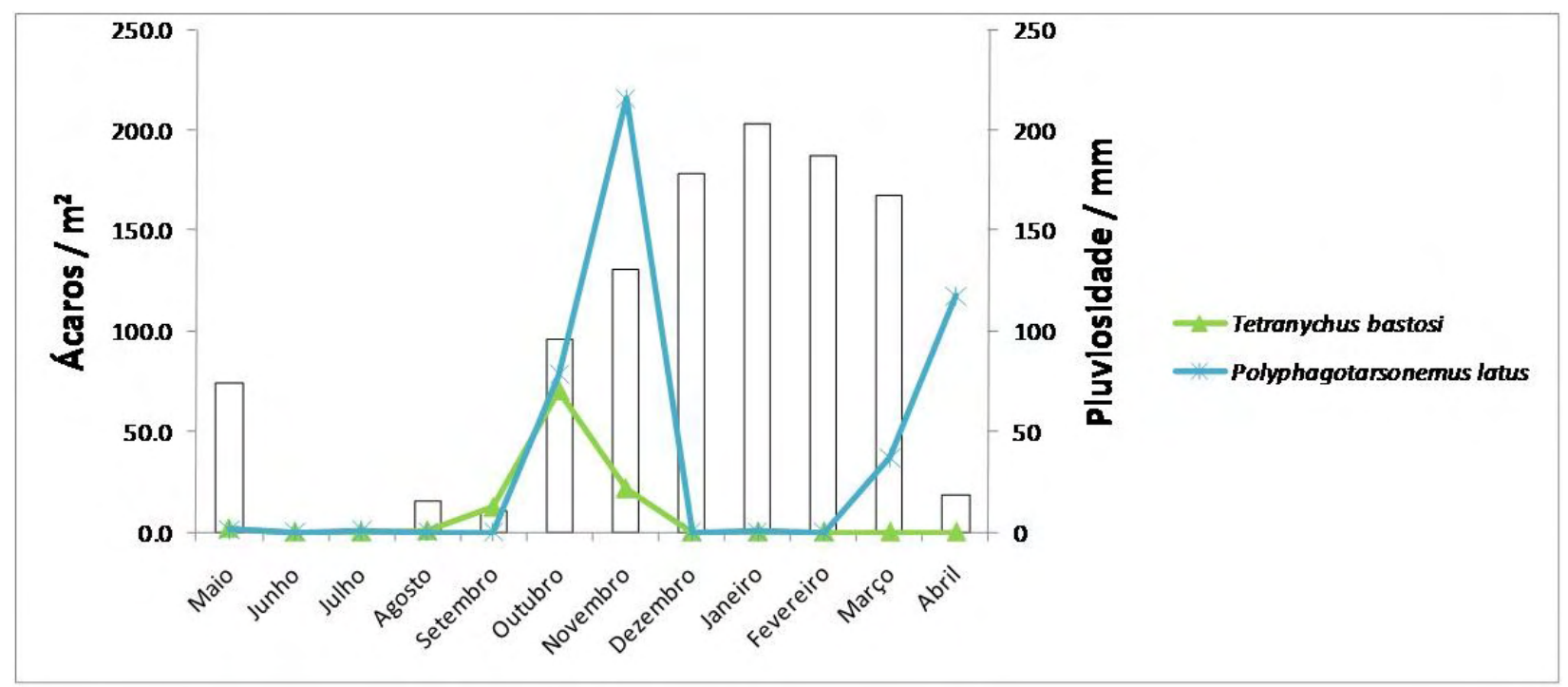

Figura 3. Ocorrência sazonal das espécies mais abundantes de ácaros fitófagos em J. curcas L. (Euphorbiaceae) na lavoura B, Jales - SP.

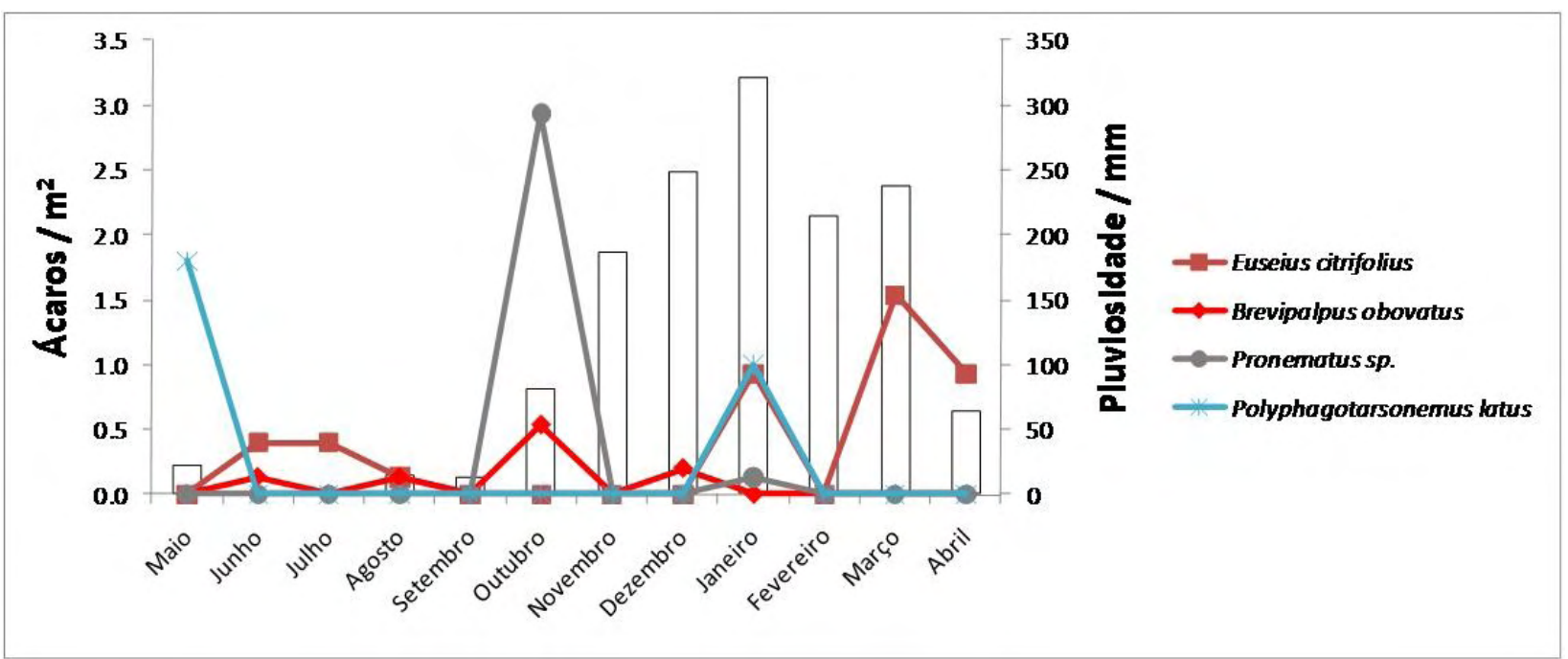

Figura 4. Ocorrência sazonal das espécies de ácaros mais abundantes em Jatropha curcas L. (Euphorbiaceae) na lavoura C, Itapagipe - MG. 


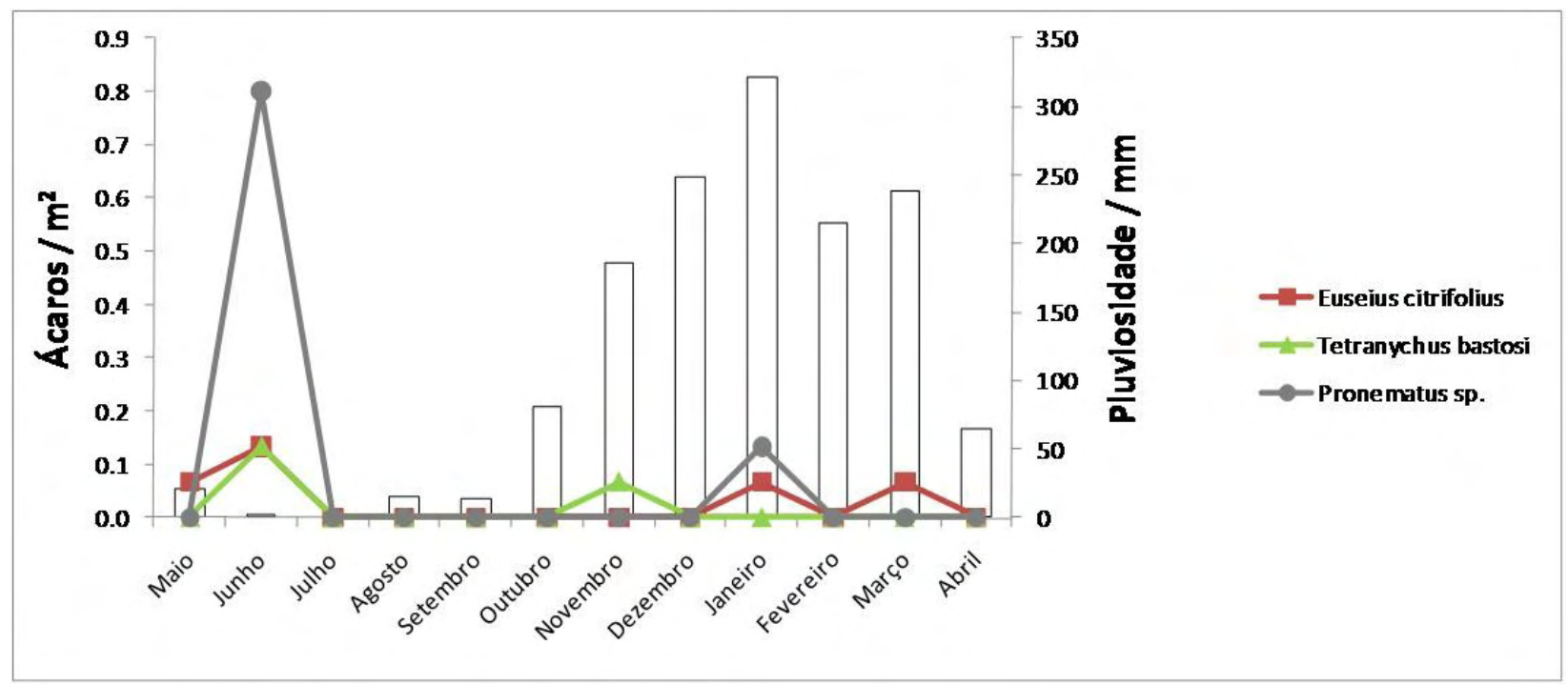

Figura 5. Ocorrência sazonal das espécies de ácaros em Jatropha curcas L. (Euphorbiaceae) na lavoura D, Itapagipe - MG.

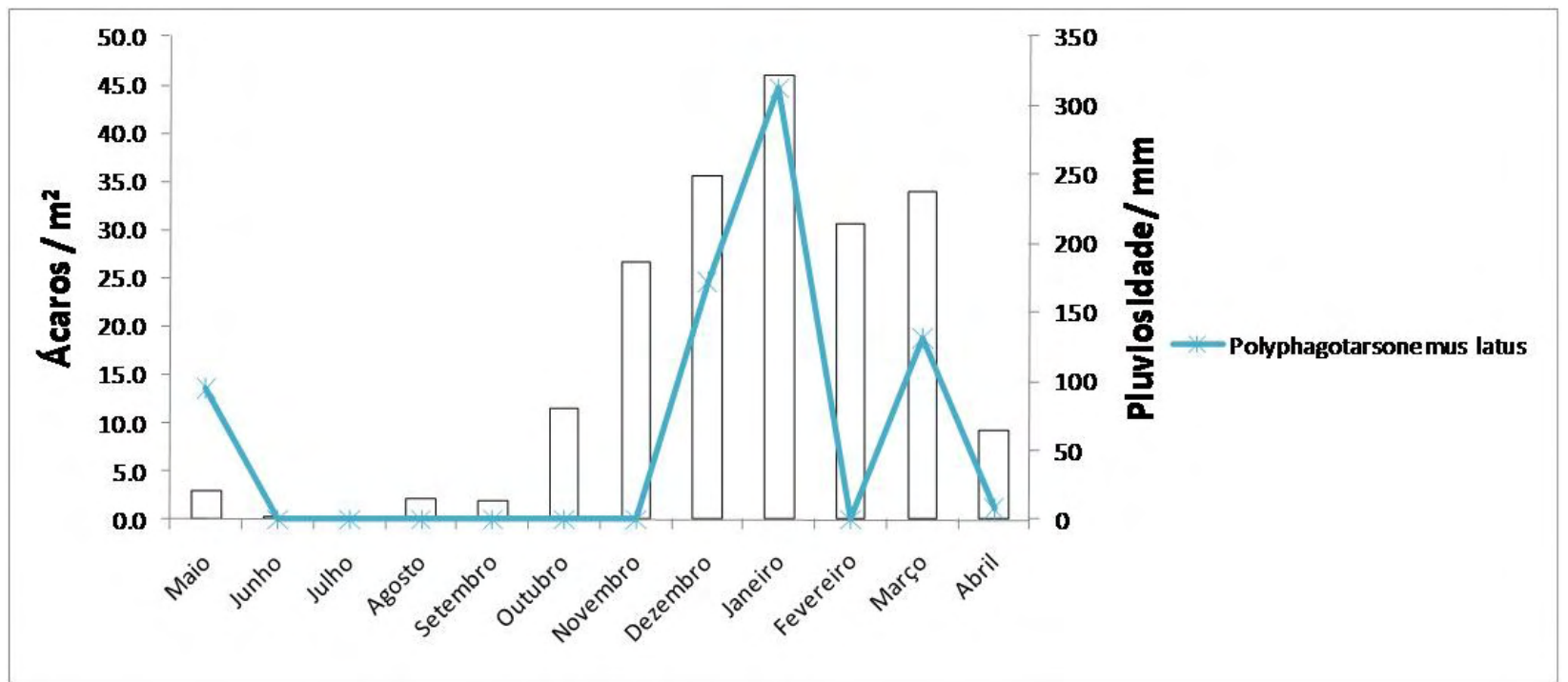

Figura 6. Ocorrência sazonal da espécie de ácaro mais abundante em Jatropha curcas L. Euphorbiaceae) na lavoura D, Itapagipe - MG. 
Tabela 2. Índices de diversidade, diversidade máxima teórica e homogeneidade das lavouras estudadas em Jales - SP e Itapagipe - MG, maio de 2008 a abril de 2009.

\begin{tabular}{|c|c|c|c|c|c|c|c|c|c|c|c|c|c|}
\hline Lavoura A & Mai & Jun & Jul & Ago & Set & Out & Nov & Dez & Jan & Fev & Mar & Abr & Índice \\
\hline$H^{\prime}$ & 0.4005 & 0.2696 & 0 & 0.2923 & 0 & 0 & 0 & 0 & 0 & 0 & 0 & 0.222 & 0.5665 \\
\hline$H \max$ & 0.7782 & 0.6021 & 0.301 & 0.301 & 0 & 0.301 & 0.301 & 0.301 & 0.301 & 0 & 0.301 & 0.6021 & 0.9542 \\
\hline e & 0.5147 & 0.4478 & 0 & 0.971 & 0 & 0 & 0 & 0 & 0 & 0 & 0 & 0.3687 & 0.5936 \\
\hline \multicolumn{14}{|l|}{ Lavoura B } \\
\hline$H^{\prime}$ & 0.7378 & 0.0932 & 0.3672 & 0.4825 & 0 & 0.3073 & 0.1433 & 0.2442 & 0.2923 & 0 & 0.0104 & 0.0469 & 0.2906 \\
\hline $\mathrm{H} \max$ & 1 & 0.301 & 0.4771 & 0.6021 & 0 & 0.6021 & 0.7782 & 0.301 & 0.301 & 0 & 0.301 & 0.699 & 1.0792 \\
\hline e & 0.7378 & 0.3095 & 0.7696 & 0.8014 & 0 & 0.5104 & 0.1841 & 0.8113 & 0.971 & 0 & 0.0344 & 0.0671 & 0.2693 \\
\hline \multicolumn{14}{|l|}{ Lavoura C } \\
\hline $\mathrm{H}^{\prime}$ & 0.5009 & 0.8095 & 0.2764 & 0.4581 & 0 & 0.1865 & 0 & 0 & 0.3853 & 0 & 0.262 & 0.1016 & 0.5532 \\
\hline$H$ max & 0.699 & 0.8451 & 0.301 & 0.4771 & 0 & 0.301 & 0 & 0 & 0.4771 & 0 & 0.301 & 0.4771 & 1 \\
\hline e & 0.7167 & 0.9579 & 0.9183 & 0.9602 & 0 & 0.6194 & 0 & 0 & 0.8075 & 0 & 0.8702 & 0.213 & 0.5532 \\
\hline \multicolumn{14}{|l|}{ Lavoura D } \\
\hline $\mathrm{H}^{\prime}$ & 0.1136 & 0.5794 & 0 & 0 & 0 & 0 & 0 & 0 & 0.0185 & 0 & 0.0102 & 0.0932 & 0.0714 \\
\hline $\mathrm{H} \max$ & 0.7782 & 0.699 & 0 & 0 & 0 & 0 & 0 & 0 & 0.6021 & 0 & 0.301 & 0.301 & 0.9542 \\
\hline e & 0.146 & 0.8289 & 0 & 0 & 0 & 0 & 0 & 0 & 0.0307 & 0 & 0.0339 & 0.3095 & 0.0748 \\
\hline
\end{tabular}

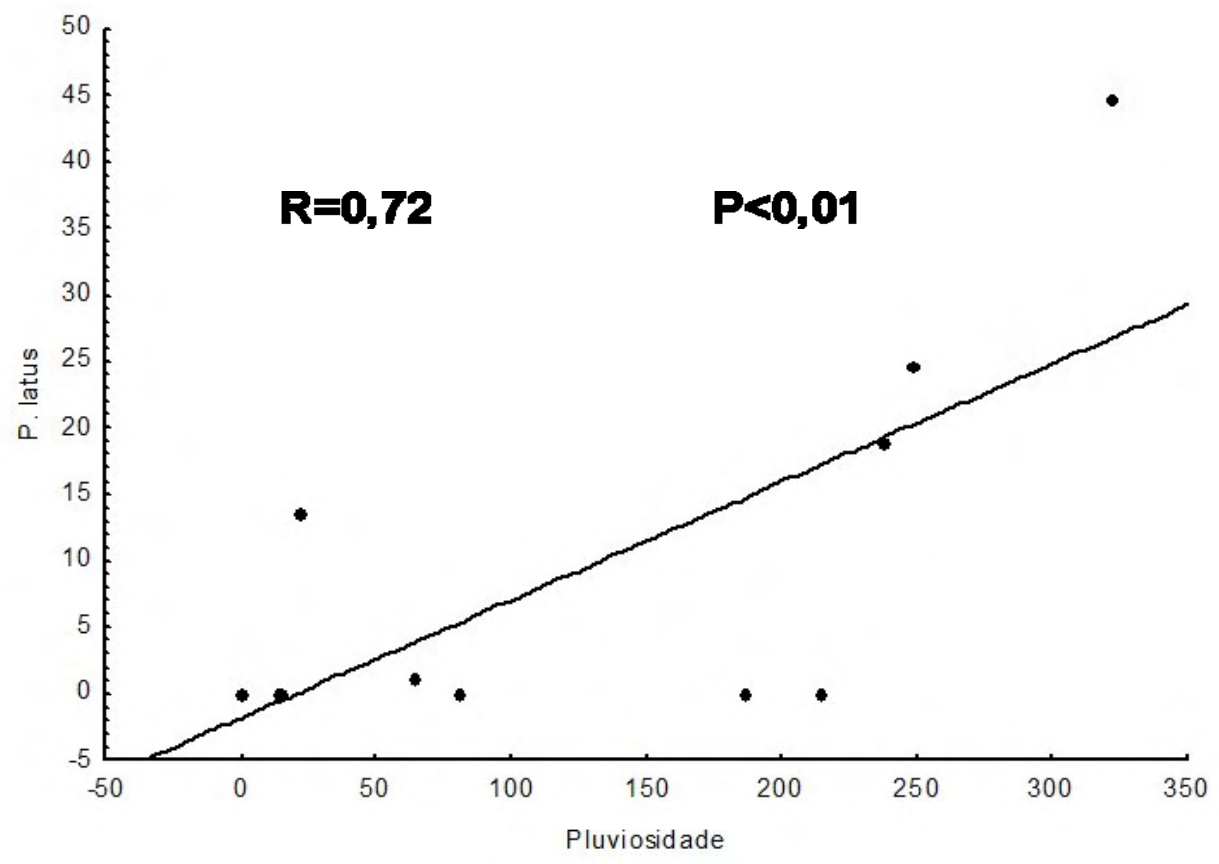

Figura 7. Correlação entre a população de $P$. latus e o índice pluviométrico na lavoura D, Itapagipe-MG, 2008/09. 


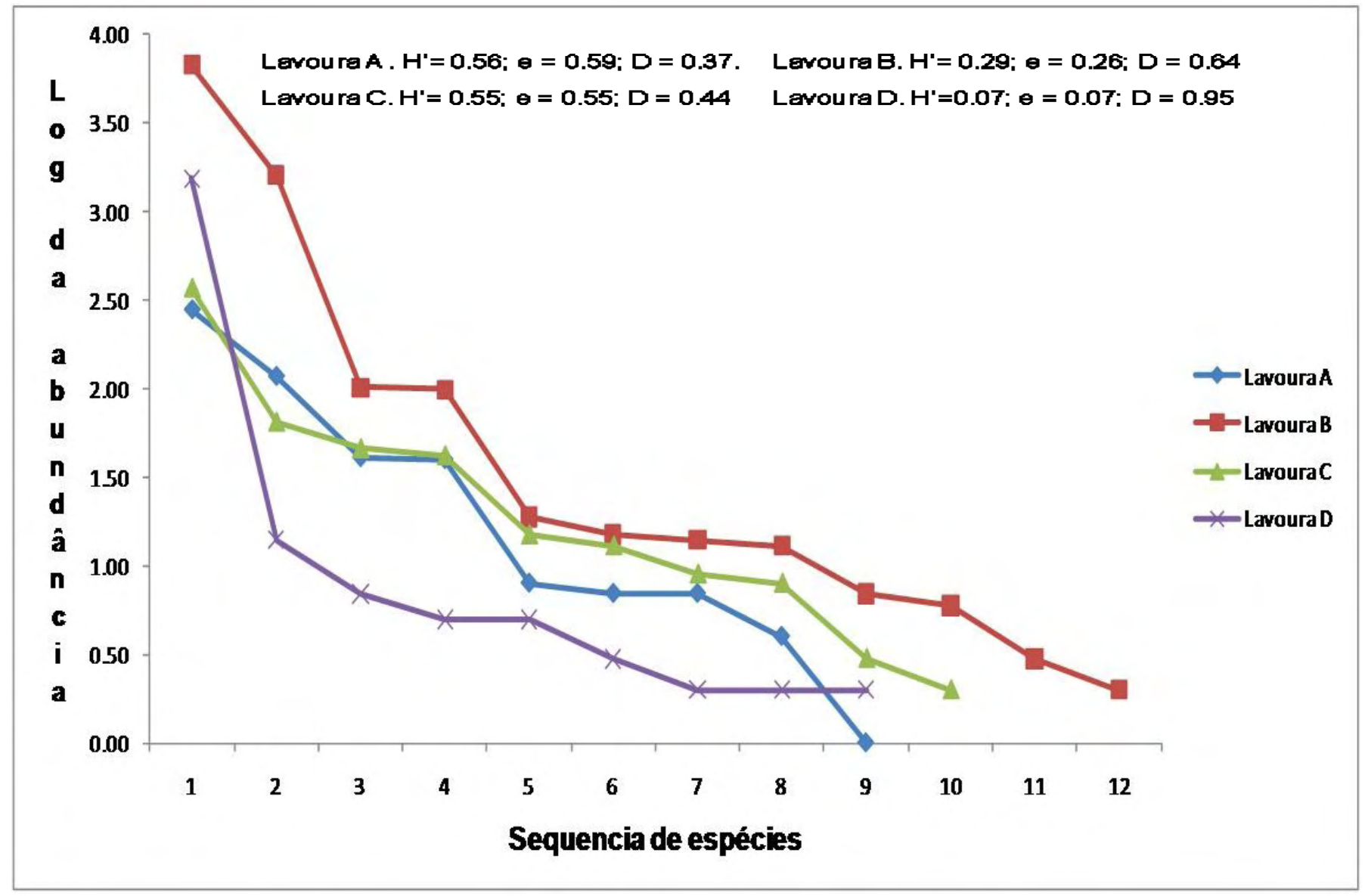

Figura 8. Curva de componente de dominância das espécies de ácaros encontradas em lavouras de J. curcas em Jales-SP e Itapagipe-MG. 
Tabela 03. Espécies de ácaros registradas em lavoura experimental em Itapagipe - MG. Número de indivíduos encontrados por área e índices de diversidade correspondentes a cada uma das áreas estudadas.

\begin{tabular}{lcc}
\hline Família / Espécie & Área sem vegetação & Área com vegetação \\
\hline Phytoseiidae & 19 & 120 \\
Euseius citrifolius & 1 & 0 \\
Iphiseiodes zuluagai & 4 & 35 \\
Thyphlodromalus aripo & 0 & 20 \\
Amblyseius acalyphus & 46 & 387 \\
\hline Tarsonemidae & 278 & 1070 \\
Polyphagotarsonemus latus & & \\
\hline Winterschmidtiidae & 5 & 5 \\
Czenspinskia sp. & 10 & 5,8451 \\
\hline Iolinidae & 0,8451 & \\
Pronematus sp. & & \\
\hline Tenuipalpidae & & \\
Brevipalpus obovatus & & \\
\hline H' & & \\
Hmax & & \\
\hline
\end{tabular}




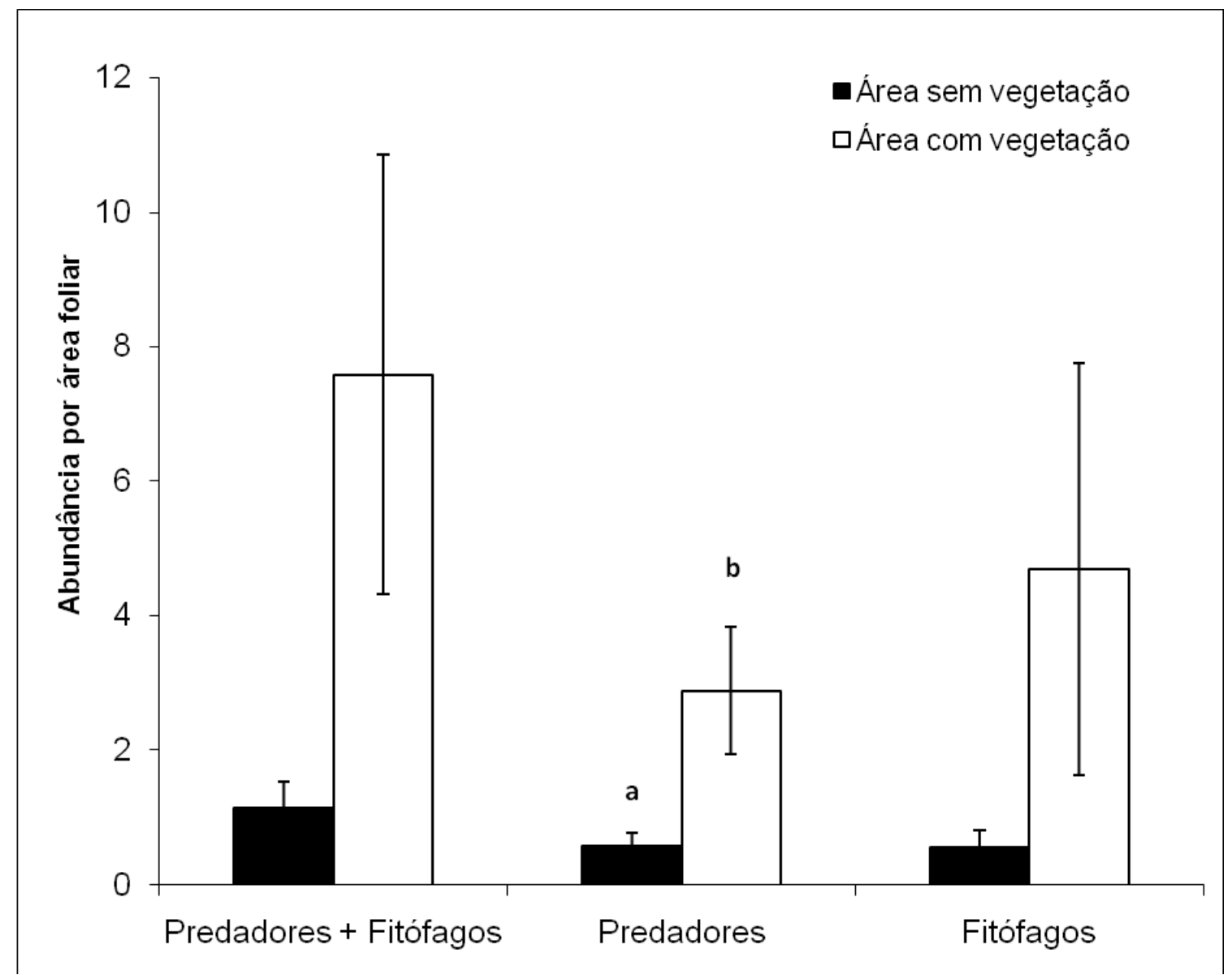

Figura 9. Médias e desvios das diferenças entre as comunidades de ácaros encontradas nos diferentes modelos de manejo em lavoura experimental de $\mathrm{J}$. curcas em Itapagipe-MG. Predadores compreendem as famílias Phytoseiidae e lolinidae e fitófagos as famílias Tarsonemidae e Tenuipalpidae. a e b indicam diferença significativa $(p=0.02)$. 


\section{Discussão}

No estudo da sazonalidade em $J$. curcas, a espécie predadora mais abundante $E$. citrifolius apresentou maior incidência nos meses mais secos nas lavouras A e B, porém, foi pouco abundante em todos os períodos nas lavoura $C$ e $D$, onde predominou os predador Pronematus sp., também com maior incidência no período seco, e inicio do chuvoso. Estudos realizados principalmente com ácaros fitoseídeos indicam que a variação na abundância pode estar ligada a fatores climáticos como a precipitação. Sato et al. (1994) em citros no estado de São Paulo, evidenciaram um pico de incidência em junho, quando a precipitação foi menor que $25 \mathrm{~mm}$. Ferla \& Moraes (1998) verificaram maior abundância de fitoseídeos em macieira, no Rio Grande do Sul, entre final de dezembro e início de fevereiro, quando ocorreu menor precipitação em relação ao restante do período amostral. Reis et al. (2000a) constataram que em pomares de citros em Minas Gerais, a predominância de fitoseídeos ocorreu nos meses em que as menores precipitações e temperaturas (abril e setembro) foram registradas. Conforme Parra et al. (2003), os ácaros predadores de maneira geral estão presentes no citros em São Paulo, nos meses de janeiro e fevereiro, e de junho a setembro. Nesse trabalho, ácaros predadores também ocorreram nos meses de janeiro e fevereiro, onde ocorreu o maior pico pluviométrico, no entanto, esses ácaros apresentaram abundância muito baixa nesse período. $O$ segundo predador mais abundante, o fitoseídeo Ricoseius loxocheles, apareceu somente na lavoura B, apenas no mês de maio, apresentando uma grande população (99). Tal fato merece atenção uma vez que esta espécie normalmente é registrada com poucos indivíduos, de 1 a 3 
(DENMARK \& MUMA, 1970; LOFEGO et al., 2004). Essa grande população de $R$. loxocheles, está muito provavelmente relacionada à presença de esporos de fungos, que sugiram em grande quantidade na mesma época e dos quais aparentemente estavam se alimentando.

De acordo com Feres et al. (2002), a redução na precipitação pode favorecer os ácaros, uma vez que, sofrem menos o efeito mecânico das chuvas, que pode removêlos das folhas. Entretanto, segundo Demite \& Feres (2005), parece que a ocorrência de chuvas ocasionais favorece as populações de ácaros em geral, mantendo a umidade relativa do ar elevada. $\mathrm{O}$ ácaro fitófago $P$. latus, por exemplo, apresentou grandes níveis de infestação durante o período de maior precipitação, conforme foi observado na lavoura $\mathrm{D}$, onde foi constatada uma correlação entre $P$. latus e o índice pluviométrico $(\mathrm{p}<0,01)$.

De acordo com Saturnino (2005), ataques severos do ácaro branco $P$. latus foram observados no mês de março de 2006 em Eldorado-MS e Nova Porteirinha-MG. Vieira et al. (2004), em trabalho realizado com mamoeiro, $P$. latus teve seu maior desenvolvimento durante o período chuvoso, a partir de outubro, provavelmente em função do aumento da umidade do ar verificados no final do inverno e começo da primavera.

Ácaros da espécie T. bastosi tiveram seu maior pico de infestação durante o final da estação seca e início da chuvosa. De acordo com Flechtmann (1981), as infestações de ácaros tetraniquídeos são favorecidas em ambientes secos, porém, no 
pinhão manso esse ácaro apareceu em grande densidade na transição entre os dois períodos.

Em vista dos dados obtidos, são consideráveis as diferenças entre as flutuações populacionais das comunidades de ácaros nas quatro lavouras. Os picos populacionais de espécies comuns a todas as áreas não foram coincidentes. E algumas espécies abundantes em uma área não ocorreram em outra.

As maiores densidades populacionais de ácaros foram registradas nas lavouras B e D, no entanto, tal densidade foi em sua maioria composta pelos ácaros fitófagos $P$. latus (Tarsonemidae) e $T$. bastosi (Tetranychidae). A lavoura B que apresentou a maior abundância de fitófagos foi à única onde foi feito o uso de agrotóxicos (enxofre). A utilização desse tipo de controle pode ter afetado a composição da comunidade acarina nessa lavoura. Segundo Croft (1990), artrópodes predadores que ocorrem de maneira natural são os agentes mais importantes no controle biológico de artrópodes fitófagos. Estudos demonstram que a toxicidade de certos defensivos agrícolas pode reduzir as populações de ácaros predadores e consequentemente afetarem sua eficácia como agentes controladores de ácaros considerados pragas (CHILDERS \& ENNS 1975; CHILDERS \& ABOU-SETTA 1999; CHILDERS et al., 2001). Desse modo, a alta densidade de ácaros fitófagos na lavoura estudada pode ter sido em parte, provocada pela baixa densidade de ácaros predadores afetados pelo defensivo em determinados períodos. O uso de produtos químicos pode também ter provocado a seleção de indivíduos mais resistentes ao principio ativo aplicado. Indivíduos não mortos em uma aplicação constituem a geração seguinte, que consequentemente será mais resistente ao defensivo (ROUSH \& MCKENZIE, 1987). 
O entorno das lavouras é um fator que pode também definir as particularidades das comunidades de ácaros de cada área estudada. De acordo com Demite \& Feres (2005), a vegetação vizinha a áreas de cultivo pode servir como reservatório para espécies predadoras, devendo ser considerada na elaboração de planos de controle ecológico de pragas.

O ácaro E. citrifolius apareceu em grande abundância nas lavouras $A$ e $B$, ambas as lavouras margeavam culturas de laranja. Essa espécie é comumente encontrada em culturas de citros (KOMATSU, 1988; MOREIRA, 1993; GRAVENA et al., 1994). Além disso, a lavoura B também fazia margem com café, onde essa espécie também tem sido registrada em grande abundância (PALLINI FILHO et al., 1992; MINEIRO et al., 2006). A menor abundância desse ácaro foi registrada na lavoura D, que possuía seu entorno exclusivamente constituído por pasto.

Outra espécie de ácaro predador, Pronematus sp., apresentou sua maior abundância na lavoura $\mathrm{C}$, onde existia um fragmento de Cerrado em uma das margens.

O ácaro Oligonychus sp. foi registrado somente na lavoura $\mathrm{B}$, em baixa densidade. Esse ácaro não foi identificado até o nível específico devido à ausência de machos, necessários para a determinação da espécie. No entanto, sabe-se que a espécie Oligonychus icilis é muito comum em culturas de café, conforme registros de Pallini Filho et al. (1992); Reis et al., (2000b) e Spongoski et al. (2005).

Dessa forma, a disparidade entre a abundância de ácaros fitófagos nas lavouras de J. curcas e a presença de algumas espécies em determinadas lavouras pode sugerir uma relação com a vegetação de entorno. 
Segundo Bellini et al. (2008), a grande abundância de ácaros fitófagos em um agroecossistema pode estar relacionada à baixa heterogeneidade ambiental e a grande disponibilidade de alimento. Isso pode ser comprovado quando observados os índices de diversidade obtidos em cada uma das lavouras. A lavoura rodeada exclusivamente por pasto (D), e a lavoura com utilização de controle químico (B), apesar de apresentarem riqueza superior ou igual às demais lavouras foram as menos diversas. Isso pode ser explicado pela dominância exercida pelas espécies de ácaros fitófagos (Figura 8).

Na lavoura A, onde o entorno foi composto por variados cultivos como manga, uva e quiabo, e na lavoura C, consorciada com milho e com entorno composto por um fragmento florestal, cana-de-açúcar e pasto, não foi observada dominância por espécies fitófagas (Figura 8). Não obstante, na lavoura A, a curva de dominância foi composta por um ácaro predador tipo IV (generalista com preferência alimentar por pólen), seguida por duas espécies fitófagas e uma micófaga. Já na lavoura C, uma espécie micófaga foi a mais abundante, seguida por duas espécies de ácaros predadores e então, uma espécie fitófaga.

No estudo realizado na lavoura experimental em Itapagipe-MG, a heterogeneidade encontrada na área onde foi mantida a vegetação espontânea pode ter fornecido recursos como abrigo e alimento para as espécies de fitoseídeos que lá se encontravam.

De acordo com trabalho desenvolvido por Beard \& Walter (2001), cada espécie de fitoseídeo pode ter necessidades especiais como, abrigos ou sítios de oviposição, que 
são encontrados somente em alguns tipos de plantas. Sendo assim, a presença de abrigos nas folhas pode ser um fator importante para a manutenção da abundância de fitoseídeos nesses vegetais (MCMURTRY \& CROFT, 1997). Isso pode se confirmar com esse experimento, de maneira que, apesar da presença de ácaros fitófagos em ambas as áreas, aquela que continha a vegetação nas entrelinhas abrigou uma abundância maior de predadores além do índice de diversidade maior. Isso se deve, muito provavelmente, por sistemas produtivos diversificados serem mais estáveis e dificultarem a multiplicação excessiva de determinada praga, permitindo que haja um melhor equilíbrio ecológico através da multiplicação de inimigos naturais e outros organismos benéficos (SOUZA, 2008).

Estudos mostram que em sistemas de plantio consorciados a abundância de inimigos naturais às pragas é maior, favorecendo também o controle biológico natural no agroecossistema em substituição aos inseticidas, seja pela eficiência dos inimigos naturais ou pela dificuldade da espécie praga encontrar a planta hospedeira (ROOT, 1973). De acordo com Togni et al. (2009), o consórcio de tomate com coentro em sistema orgânico mostrou ser mais eficiente do que em sistema convencional no controle populacional de mosca-branca em tomate, podendo reduzir os danos causados à cultura. O consórcio favoreceu o estabelecimento de uma maior abundância de inimigos naturais e menor densidade de ninfas da mosca-branca nas plantas de tomate. Portanto, o policultivo tomate-coentro, principalmente em sistemas orgânicos, foi favorável ao controle biológico natural de mosca-branca.

Estudos realizados por Bragança et al. (1998) e Zanuncio et al., (1998) indicam que a presença de vegetação nativa nos plantios de eucalipto pode melhorar a 
distribuição de himenópteros inimigos naturais e, com isso, reduzir as populações de lepidópteros pragas nesses plantios. Zaffaroni \& Santana (1983), demonstraram que em culturas de milho sem consorciação o dano causado pela lagarta Spodoptera frugiperda foi muito maior do que em sistemas de milho consorciado.

No entanto os ácaros predadores encontrados neste trabalho não estavam efetivamente controlando as populações de ácaros fitófagos. Apesar de ácaros predadores representarem efetivos agentes no controle de ácaros fitófagos, principalmente os da família Phytoseiidae (MCMURTRY \& CROFT, 1997; GERSON et al., 2003), os ácaros predadores encontrados nesse trabalho, provavelmente utilizavam esporadicamente os fitófagos como um incremento para a manutenção de suas populações e não como seu principal item alimentar. Dessa forma os altos níveis de infestação de ácaros fitófagos poderiam servir como um suporte para a manutenção das populações de E. citrifolius na ausência de outro item alimentar. Trabalhos indicam que espécies do gênero Euseius podem utilizar pólen de algumas espécies vegetais como alimento (DAUD \& FERES 2004; MACMURTRY \& CROFT, 1997). Esse fato reforça a relação de ácaros predadores com a heterogeneidade ambiental presente na área experimental, e que esse tipo de manejo pode auxiliar a composição da acarofauna em J. curcas. 


\section{Referências}

ASSUNÇÃO, M. P; NIED, A.H; VENDRUSCOLO, M. C; FRASSON, D. B; SOARES, V. M. 2009. Inflorescências do pinhão manso no primeiro e Segundo ano agrícola submetido a diferentes fontes de adubação. Universidade Federal do Mato Grosso. $2^{\circ}$ jornada científica da Unemat.

ALTIERI, M. A; SILVA N. E; NICHOLLS, C. I. 2003. O papel da biodiversidade no manejo de pragas. Ribeirão Preto, Editora Holos Ltda, 226p.

BEARD, J. J; WALTER, G. H. 2001. Host plant specificity in several species of generalist mite predators. Ecological Entomology. Vol. 26, no. 6, pp. 562-570.

BELLINI, M. R; MORAES, G. J; FERES, R. J. F. 2005a. Ácaros (Acari) de dois sistemas de cultivo da seringueira no Noroeste do estado São Paulo. Neotropical Entomology. v. 34, n. 3. p. 475-484.

BELLINI, M. R; MORAES, G. J; FERES, R. J. F. 2005b. Plantas de ocorrência espontânea como substratos alternativos para fitoseídeos (Acari: Phytoseiidae) em cultivos de seringueira Hevea brasiliensis Muell. Arg.(Euphorbiaceae), 22: $35-42$.

BELLINI, M. R; FERES, R. J. F; BUOSI, R. (2008) Ácaros (Acari) de seringueira (Hevea brasiliensis, Euphorbiaceae) e de euforbiáceas espontâneas no interior dos cultivos. Neotropical Entomology, v. 37, p. 463-471.

BRAGANÇA, M. A. L; JANUNCIO, J. C; PIANÇO, M; LARANJEIRO, A. J. 1998. Effects of environmental heterogeneity on Lepidoptera and Hymenoptera populations in Eucalyptusplantations in Brazil. Forest Ecology and Management. v. 103, p. 287292.

CHILDERS, C. C; ENNS, W. R. 1975. Predaceous arthropods associated with spider mites in Missouri apple orchards. Journal of the Kansas Entomological Society, v. 48, n. 4 p. 453-471.

CHILDERS, C. C; ABOU-SETTA, M. M. 1999. Yield reduction in 'Tahiti' lime from Panonychus citri feeding injury following different pesticide treatment regimes and impact on the associated predacious mites. Experimental and Applied Acarology. v. 23, p. 771-783. 
CHILDERS, C. C; AGUILAR, H; VILLANUEVA, R; ABOU-SETTA, M. M. 2001. Comparative residual toxicities of pesticides to the predator Euseius mesembrinus (acari: phytoseiidae) on citrus in florida. Florida Entomologist. v.84, n.3.

CROFT, B. A. 1990. Arthropod Biological Control Agents and Pesticides. NewYork: Wiley Intersci. $723 \mathrm{p}$.

DAUD, R. D; FERES, R. J. F. 2004. O valor de Mabea fistulifera Mart. (Euphorbiaceae), planta nativa do Brasil, como reservatório para o predador Euseius citrifolius Denmark \& Muma (Acari, Phytoseiidae). Revista Brasileira de Zoologia. v.21, n. 3, p. $453-458$.

DAUD, R. D; FERES, R. J. F. 2005. Diversidade e flutuação populacional de ácaros (Acari, Arachnida) em Mabea fistulifera Mart. (Euphorbiaceae) de dois fragmentos de Mata Estacional Semidecídua em São José do Rio Preto, São Paulo, Brasil. Neotropical Entomology, Londrina, v. 34, n. 2, p. 191-201.

DAUD, R. D; FERES, R. J. F. 2007. Dinâmica populacional de ácaros (Acari, Eriophyidae, Tenuipalpidae) em seis clones de seringueira no sul do estado do Mato Grosso. Revista Brasileira de Entomologia. v. 51, n. 3. p. 377-381.

DEMITE, P.R; FERES, R. J. F. 2005. Influência de Vegetação Vizinha na Distribuição de Ácaros em Seringal (Hevea brasiliensis Muell. Arg., Euphorbiaceae) em São José do Rio Preto, SP. Neotropical Entomology. v. 34, p.829-986.

DEMITE, P.R; FERES, R. J. F. 2005. Ocorrência e flutuação populacional de ácaros associados à seringuais vizinhos de fragmentos de cerrado. Neotropical Entomology. v. 36, n.1 p.117-127.

DEMITE, P.R; FERES, R. J. F. 2008. Influência de Fragmentos de Cerrado na Distribuição de Ácaros em Seringal. Neotropical Entomology, v.37, n2.

DIAS, L. A. DOS S; LEME, L. P; LAVIOLA, B. G; PALLINI, A; PEREIRA, O. L; DIAS, D. C. F. S; CARVALHO, M; MANFIO, C. E; SANTOS, A. S; SOUSA, L. C. A; OLIVEIRA, T. S; PRETTI, L. A. 2007. Cultivo de pinhão manso (Jatropha curcas L.) para produção de óleo combustível, Viçosa, Editora UFV, 40p.

FERES, R. J. F; ROSSA-FERES, D. C; DAUD, R. D; SANTOS, R. S. 2002. Diversidade de ácaros (Acari: Arachnida) em seringueiras (Hevea brasiliensis Muell. Arg., 
Euphorbiaceae) na região noroeste do estado de São Paulo, Brasil. Revta Bras. Zool. v. 19, n. 1, p. 137-144.

FERES, R. J.F; MORAES, G. J. 1998. Phytoseiid mites (Acari: Phytoseiidae) from wood areas in the State of São Paulo, Brazil. Systematic and Applied Acarology. v3, p. 125-132.

FLECHTMANN, C. H. W. 1975. Elementos de Acarologia. Livraria Nobel S.A., São Paulo.

FLECHTMANN, C.H.W. 1981. Ácaros de importância agrícola. Livraria Nobel S.A., São Paulo.

GERSON, R; SMILEY, R. L; OCHOA, R. 2003. Mites (Acari) for pest control. Oxford, Blackwell Publishing, 539p.

GRAVENA, S.; BENETOLI, I; MOREIRA, P.H.R; YAMAMOTO, P.T. 1994. Euseius citrifolius Denmark \& Muma predation on citrus leprosis mite Brevipalpus phoenicis (Geijskes) (Acari: Tenuipalpidae). An. Soc. Entomol. Brasil 23:209218.

JEPPSON, L. R; KEIFER H. H; BAKER E. W. 1975. Mites injurious to economic plants. Berkeley, University of California Press, 614p.

KOMATSU, S.S. \& NAKANO, O. 1988. Estudos visando o manejo do ácaro da leprose em citros através do ácaro predador Euseius concordis (Acari: Phytoseiidae). Laranja 9:123-145.

LOFEGO, A.C; MORAES, G.J. 2006. Ácaros (Acari) associados a Mirtáceas (Myrtaceae) em áreas de cerrado no estado de São Paulo com análise faunística das famílias Phytoseiidae e Tarsonemidae. Neotropical Entomology. v. 35, n. 6. p. 731-746.

LOFEGO, A.C; MORAES, G.J; Castro, L.A.S. 2004. Phytoseiid mites (Acari: Phytoseiidae) on Myrtaceae in the State of São Paulo, Brazil. Zootaxa. 516:1-18.

MARTINS, A. P. 2009. Dissertação de Mestrado. Bacia do ribeirão Cachoeira de Cima, Itapagipe - MG: Avaliação ambiental integrada e alternativas de uso. Universidade Federal de Uberlândia. 225 p.

MCMURTRY, J.A. \& CROFT, B.A. 1997. Life-styles of phytoseiid mites and their roles in biological control. Annual Review of Entomology. v. 42, p. 291-321. 
MINEIRO, J. L. C; SATO, M. E; RAGA, A; ARTHUR, V; MORAES, G. J; SARRETA, F. O; CARRIJO, A. 2006. Diversidade de ácaros (Arachnida: Acari) em Coffea arabica L. cv. Mundo Novo, nos municípios de Jeriquara e Garça, Estado de São Paulo. Biota Neotropica, v6, n2.

MORAES, G. J; FLACHTMANN, C. H. W. 2008. Manual de Acarologia: Acarologia básica e ácaros de plantas cultivadas no Brasil. Editora Holos. 288 p.

MOREIRA, P.H.R. 1993. Ocorrência, dinâmica populacional de ácaros predadores em citros e biologia de Euseius citrifolius (Acari: Phytoseiidae). Dissertação de mestrado, FCAVJ / UNESP, Jaboticabal, 110p.

PALLINI FILHO, A; MORAES, G.J; BUENO, V.H.P. 1992. Ácaros associados ao cafeeiro (Coffea arabica L.) no sul de Minas Gerais. Ciência e Prática, v.16, p.303-307.

PARRA, J. R. P; OLIVEIRA, H. N; PINTO, A. S. 2003. Guia ilustrado de pragas e insetos benéficos dos citros. Piracicaba, A. S. Pinto, 140p.

REIS, P. R; CHIAVEGATO, L. G; ALVES, E. B; SOUSA, E. O. 2000a. Ácaros da família Phytoseiidae associados aos citros no município de Lavras, Sul de Minas Gerais. An. Soc. Entomol. Bras. v.29, p. 95-104.

REIS, P.R; SOUZA, J.C; SOUZA, E. O; TEODORO, A.V. 2000b. Distribuição espacial do ácaro Brevipalpus phoenicis (Geijskes) (Acari: Tenuipalpidae) em cafeeiro (Coffea arabica L.). An. Soc. Entomol. Brasil 29:177-183.

ROOT, R. B. 1973. Organization of a Plant-Arthropod Association in Simple and Diverse Habitats: The Fauna of Collards (Brassica oleracea). Ecological Monographs. v. 43, n. 1, p. 95-124.

ROUSH, R. T; MCKENZIE, J. A. 1987. Ecological genetics of insecticide and acaricide resistence. Ann. Rev. Entomol. v. 32. p. 361-380.

SATO, M. E; RAGA, A; CERÁvolo, L. C; ROSSI A. C; POTENZA, M. R. 1994. Ácaros predadores em pomar cítrico de Presidente Prudente, estado de São Paulo. An. Soc. Entomol. Brasil. v. 23, p. 435-441.

SOUZA, J. L. 2008. Importância, tendência e perspectivas ambientais da produção orgânica de hortaliças. XX Congresso Brasileiro de Fruticultura 54th Annual Meeting of the Interamerican Society for Tropical Horticulture. Vitória/ES. 
SPONGOSKI, S; REIS, P.R; ZACARIAS, M.S. 2005. Acarofauna da cafeicultura de cerrado em Patrocínio, Minas Gerais. Ciênc. Agrotéc. 29:9-17.

TOGNI, P. H. B; Frizzas, M. R; Medeiros, M. A; Nakasu, E. Y. T; Pires, C. S. S; Sujii, E. R. 2009. Dinâmica populacional de Bemisia tabacibiótipo B em tomate monocultivo e consorciado com coentro sob cultivo orgânico e convencional. Hortic. Bras. v.27 n.2.

VIEIRA, M. R; CORREA, L. S; CASTRO, T. M. M. G; SILVA, L. F. S; MONTEVERDE, M. S. 2004. Efeito do cultivo do mamoeiro em ambiente protegido sobre a ocorrência de ácaros fitófagos. Rev. Bras. Frutic., Jaboticabal - SP, v. 26, n. 3, p. 441-445.

ZAFFARONI, E; SANTANA, J. C. F. (1983). Incidência de insetos em sistemas isolados e consorciados de milho (Zea mays L.) e feijão (Phaseolus vulgaris L.). Agropecuária Técnica, v. 4, n. 1, 8p.

ZANUNCIO, J. C; BATALHA, V. C; GUEDES, R. N. C; PICANÇO, M. C. 1998. Insecticide selectivity to Supputius cincticeps (Stal) (Het.: Pentatomidae) and its prey Spodoptera frugiperda (J.E. Smith) (Lep.: Noctuidae). Journal of Applied Entomology, Berlin, v. 122, n. 3, p. 457-460. 


\section{Conclusões}

Esse estudo registrou 25 espécies de ácaros associados ao Pinhão manso, número bem maior do que já havia sido relatado em literatura.

A presença dos ácaros fitófagos Polyphagotarsonemus latus, e Tetranychus bastosi, encontrados em grandes infestações em pinhão manso, é um indício de que esses ácaros podem ocasionar danos na implantação dessa espécie vegetal em forma de cultivo.

Os estudos sobre a sazonalidade poderão ser informações importantes na implementação de planos de controle de espécies praga. $O$ fato da flutuação das populações apresentarem particularidades em cada lavoura é um indicativo de que muito provavelmente o manejo de cada uma dessas lavouras, assim como o entorno devem exercer influencia na comunidade de ácaros em pinhão. No entanto, pelo menos um ponto em comum foi detectado em todas as lavouras, a maior abundância de $P$. latus na época úmida. Dessa forma, essas informações devem ser consideradas na implantação de novas lavouras. Entretanto, novos estudos ainda devem ser feitos, visando, por exemplo, detectar bons predadores para ácaros-praga em pinhão manso, tendo em vista que, não foi possível observar uma possível ação de controle por parte dos predadores mais abundantes encontrados. 
Autorizo a reprodução xerográfica para fins de pesquisa.

São José do Rio Preto, 20/04/2010.

Rodrigo Luiz Costa Verona 